\title{
EL SISTEMA DE APOYO EN LA TOMA DE DECISIONES DESDE LA CONVENCIÓN INTERNACIONAL SOBRE LOS DERECHOS DE LAS PERSONAS CON DISCAPACIDAD: PRINCIPIOS GENERALES, ASPECTOS CENTRALES E IMPLEMENTACIÓN EN LA LEGISLACIÓN ESPAÑOLA
}

\author{
Patricia CUENCA GÓMEZ* \\ AYUdANTE DOCTORA DE FILOSOFÍA DEL DERECHO \\ UNIVERSIDAD CARLOS III DE MADRID
}

SUMARIO: I.Introducción II. El sistema de sustitución en la toma de decisiones en la legislación española. II.I. Principios generales II.2. Aspectos centrales. III. El sistema de apoyo en la toma de decisiones en la Convención Internacional sobre los Derechos de las Personas con Discapacidad III.I. Principios generales III.2. Aspectos centrales. IV. La implementación del sistema de apoyo en la legislación española. Algunas propuestas. IV. I. Cambios en la normativa básica reguladora de los derechos de las personas con discapacidad IV.2. Cambios en el régimen general de capacidad jurídica IV.3. Cambios en las condiciones de ejercicio de los derechos y realización de actos jurídicos. V. Venciendo resistencias y planteando cuestiones clave.

RESUMEN: La Convención Internacional sobre los Derechos de las Personas con Discapacidad establece un importante cambio de paradigma en la regulación de la capacidad jurídica que consiste en el paso del sistema de sustitución al sistema de apoyo en la toma de decisiones. En el presente trabajo pretendo dar cuenta de las principales dimensiones de este cambio, realizar algunas propuestas para la implementación del sistema de apoyo en la legislación española y plantear algunas cuestiones clave para el éxito del nuevo modelo.

PAlabras Clave: capacidad jurídica, discapacidad, sistema de apoyo en la toma de decisiones, sistema de sustitución en la toma de decisiones.

Abstract: The Convention on the Rights of Persons with Disabilities establishes an important paradigm shift in legal capacity regulation, moving from the substitution decision making system to the supported decision making system. This paper aims to examine the main dimensions of this change, proposes some reforms to its implementation in Spanish Law and discusses some key points to the success of the new model of supported decision making.

KEYwORDS: disability, substitution decision making system, supported decision making sytem, legal capacity.

\footnotetext{
* Instituto de Derechos Humanos «Bartolomé de las Casas» y Departamento de Derecho Internacional Público, Derecho Eclesiástico del Estado y Filosofía del Derecho. Este trabajo se ha desarrollado en el marco de los proyectos Consolider-Ingenio 2010 «El tiempo de los derechos» (CSD2008-00007), «Dis-capacidad, independencia y Derechos Humanos» (DER 20II-22729) y «Estudio, implementación y seguimiento sobre Capacidad Jurídica de la CDPD en los ordenamientos jurídicos locales» coordinado por la Red Iberoamericana de Expertos en la Convención Internacional sobre los Derechos de las Personas con Discapacidad y financiado por el Open Society Institute.
} 


\section{Introducción}

Es común señalar que la Convención Internacional sobre los Derechos de las Personas con Discapacidad (en adelante CDPD) ${ }^{\mathrm{I}}$ supone una auténtica revolución respecto del tratamiento de la capacidad jurídica en las legislaciones nacionales. Esta revolución suele sintetizarse en el paso del «modelo de sustitución» en la toma de decisiones, que parte de la configuración tradicional del sistema de incapacitación, a un nuevo «modelo de apoyo» o «asistencia» en la toma de decisiones que trata de hacer realidad la igualdad de las personas con discapacidad en el ejercicio de su capacidad jurídica² .

El cambio de modelo propugnado por el artículo i2 de la CDPD sigue siendo una cuestión pendiente en muchos Estados parte, y también en el Estado español.

El Comité sobre los Derechos de las Personas con Discapacidad, órgano de vigilancia de la CDPD, en sus Observaciones finales ${ }^{34}$. sobre el informe inicial presentado por España mostró su preocupación por la falta de medidas «para reemplazar la sustitución en la adopción de decisiones por la asistencia para la toma de decisiones en el ejercicio de la capacidad jurídica» y recomendó la revisión de «las leyes que regulan la guarda y la tutela» y la adopción de «medidas para adoptar leyes y políticas por las que se reemplacen los regímenes de sustitución en la adopción de decisiones por una asistencia para la toma de decisiones que respete la autonomía, la voluntad y las preferencias de la persona. Se recomienda, además, que se proporcione formación sobre esta cuestión a todos los funcionarios públicos $y$ otros interesados pertinentes».

El legislador español -a pesar de los compromisos expresamente asumidos en diferentes momentos- ha venido retrasando la reforma del sistema de incapacitación ${ }^{5}$ y los

\footnotetext{
${ }^{\text {I }}$ Aprobada el I3 de diciembre de 2006 por la Asamblea General de Naciones Unidades en Nueva York. El instrumento de ratificación de la Convención se publicó en España el 2I de abril de 2008, BOE núm. 96.

${ }^{2}$ PALACIOS, A., El modelo social de la discapacidad. Orígenes, caracterización y plasmación en la Convención Internacional sobre los derechos de las personas con discapacidad, Colección CERMI, Madrid, CINCA, 2008, págs., 420 y ss.

${ }^{3}$ Estas Observaciones pueden consultarse en la web del Comité:

http://www.ohchr.org/EN/HRBodies/CRPD/Pages/Session6.aspx

fecha de consulta I5 de noviembre de 2012 .

${ }^{4}$ Igualmente, el Comité hizo referencia a la necesidad de reformar otras cuestiones estrechamente relacionadas con el ejercicio de la capacidad jurídica, como la regulación de la privación del derecho de sufragio, de los internamientos o de las esterilizaciones forzosas y a de extender los conceptos de personas con discapacidad y de discriminación por motivos de discapacidad.

${ }^{5}$ En efecto, en 2009 la Disposición Final primera de la Ley I/2009, de 25 de marzo, de reforma de la Ley de 8 de junio de I957, sobre el Registro Civil, en materia de incapacitaciones, cargos tutelares y administradores de patrimonios protegidos, de la Ley 4I/2003, de I8 de noviembre, sobre protección patrimonial de las personas con discapacidad y de modificación del Código Civil y de la Ley de Enjuiciamiento Civil de la normativa tributaria con esta finalidad, BOE núm. 73 de 26 de marzo de 2009 , estableció que «El Gobierno, en el plazo de seis meses desde la entrada en vigor de esta Ley, remitirá a las Cortes Generales un Proyecto de Ley de reforma de la legislación reguladora de los procedimientos de incapacitación judicial, que pasarán a denominarse procedimientos de modificación de la capacidad de obrar, para su adaptación a las previsiones de la Convención Internacional sobre los Derechos de las Personas con Discapacidad, adoptada por Naciones Unidas el 13 de diciembre de 2006». Tras incumplirse este compromiso, la Ley 26/20II, de I de agosto, de adaptación normativa a la Convención Internacional sobre los Derechos de las Personas con Discapacidad, BOE núm. I84 de 2 de agosto de 2OII estableció un nuevo plazo para proceder a reformar la normativa española en materia de capacidad jurídica. Su disposición adicional séptima señala que «El Gobierno, en el plazo de un año a partir de la entrada en vigor de esta Ley, remitirá a las Cortes Generales un proyecto de ley de adaptación normativa del ordenamiento jurídico para dar cumplimiento al artículo 12 de la Convención Internacional sobre los Derechos de las Personas con Discapacidad, en lo relativo al ejercicio de la capacidad jurídica por las personas con discapacidad, en igualdad de condiciones que las demás en todos los aspectos de la vida. Dicho proyecto de ley establecerá las modificaciones necesarias en el proceso judicial de determinación de apoyos para la toma libre de decisiones de las personas con discapacidad que los precisen». Este segundo plazo también se ha incumplido. Aunque el 29 de junio de 2012 se aprobó en el Congreso de los Diputados una proposición no de ley instando al Gobierno a que presentase el proyecto de reforma, todavía no se ha enviado dicho proyecto.
} 
jueces y tribunales nacionales tampoco han mantenido, con algunas excepciones, una actitud suficientemente activa en la implementación del modelo de apoyo por el que aboga el artículo I2 de la CDPD en el nivel aplicativo. Además, de los pronunciamientos que se han producido en ambos contextos -legislativo ${ }^{6}$ y judicial7 - parece desprenderse que los poderes públicos españoles no terminan de ser plenamente conscientes del calado y del alcance de las modificaciones normativas que es necesario llevar a cabo para instaurar un auténtico sistema de apoyo en la toma de decisiones que garantice a las personas con discapacidad el ejercicio de su capacidad jurídica, sin discriminación alguna, en «todos los aspectos de la vida» 8

A mi modo de ver, la adecuada implementación de este sistema reclama una mutación profunda de los principios que han venido inspirando la regulación de la capacidad jurídica en el sistema español y un cambio sustancial en los aspectos centrales de esta normativa. De tales transformaciones pretendo dar cuenta en los apartados primero y segundo del presente trabajo. Desde estas premisas plantearé en el apartado tercero algunas propuestas de lege ferenda para la articulación concreta del sistema de apoyo en la toma de decisiones en la normativa española que, como se comprobará, van mucho más allá de la reforma de la legislación civil. Finalmente, expondré ciertas resistencias que es necesario vencer para la puesta en marcha del nuevo sistema y algunas cuestiones que considero clave para su éxito.

\section{El sistema de sustitución en la toma de decisiones en la legislación española}

En este apartado analizaré de manera sucinta los elementos medulares del sistema de sustitución en la toma de decisiones vigente en la legislación española, en gran medida compartidos en otros sistemas jurídicos. Para ello, daré cuenta, en primer lugar, de los principios generales que inspiran este sistema y me referiré, en segundo lugar, a los aspectos esenciales de su regulación concreta.

\section{II.I. Principios generales}

El sistema de sustitución en la toma de decisiones, como antes se señaló, parte de la configuración tradicional de la institución de la incapacitación basada en un enfoque

\footnotetext{
${ }^{6}$ En este sentido pueden consultarse el «Informe sobre las medidas necesarias para la adaptación de la Legislación a la Convención de la ONU sobre los Derechos de las Personas con Discapacidad» elaborado por una Comisión Interministerial y aprobado por el Consejo de Ministros el 30 de marzo de 2010 y el «Primer Informe sobre medidas adoptadas en cumplimiento de Convención Internacional sobre los Derechos de las Personas con Discapacidad» presentado ante el Comité sobre los Derechos de las Personas con Discapacidad en cumplimiento de la obligación establecida en el art. 35 de la Convención el 5 de mayo de 2010 . Ambos contienen propuestas que se limitan a la realización de ajustes terminológicos, y no tanto de fondo y a retoques de detalle del sistema vigente de incapacitación para hacerlo más soportable. Un análisis pormenorizado de los pronunciamientos de estos informes en relación con la cuestión de la capacidad jurídica puede verse en CUENCA GÓMEZ, P., Los derechos de las personas con discapacidad, Madrid, Cuadernos de la Cátedra de Democracia y Derechos Humanos de la Universidad de Alcalá y el Defensor del Pueblo, 20I2, págs. 2i6 y ss.

${ }^{7}$ En este punto debe mencionarse la Sentencia del Tribunal Supremo, STS de 29 de abril de 2009 , sala de lo civil, núm. 282/2009, RJ 2009/290I, que, manejando un enfoque médico, afirmó la compatibilidad del sistema de incapacitación con la Constitución española y con la CDPD. Un análisis crítico de esta sentencia puede verse en Idem y en CUENCA GÓMEZ, P., «La capacidad jurídica de las personas con discapacidad: el art.I2 de la Convención de la ONU y su impacto en el Ordenamiento jurídico español», Derechos y libertades, núm. 24, 20II, págs. 74-96. Vid. también PÉREZ DE ONTIVEROS BAQUERO, C., «Comentario a las sentencia de 29 de abril de 2009", Cuadernos Civitas de Jurisprudencia Civil, núm. 82, enero-abril 20ıo, págs. 34I y 342. Igualmente puede consultarse CAMPO IZQUIERDO, A.L., «Comentarios a la Sentencia del Tribunal Supremo de 29/04/2009. Una comparativa en relación con la Sentencia del Tribunal. Supremo de 3I/I2/I99I»,

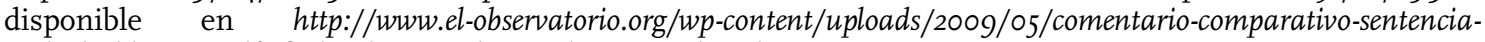
2gdeabrilde2009.pdf; fecha de consulta 20 de noviembre de 2012).

${ }^{8}$ Tal y como exige el apartado 2 del artículo I2 de la CDPD.
} 
propio del Derecho privado e inspirada en una concepción de la discapacidad anclada en el modelo médico y en la perspectiva asistencialista.

Desde los presupuestos del modelo médico ${ }^{9}$ se considera que las dificultades que algunas personas con discapacidad -básicamente, aunque no sólo personas con discapacidad mental o intelectual- pueden encontrar en la toma de sus decisiones están ocasionadas exclusivamente por sus déficits cognitivos que les impiden adoptar sus elecciones de una forma «normal», esto es, de manera racional, autónoma, responsable e independiente. De este modo, se justifica como una consecuencia natural e inevitable que las personas con discapacidad que no pueden superar sus «desviaciones» vean restringida o incluso anulada su capacidad jurídica y que sean reemplazadas por un tercero «capacitado» en la toma de sus decisiones. Asumiendo esta visión la regulación del sistema de incapacitación en la legislación española se orienta de detectar los déficits individuales que permiten limitar la capacidad jurídica - de obrar, según la terminología empleada por nuestro legislador- y la consecuente sustitución de las personas con discapacidad en sus elecciones y en el ejercicio de sus derechos.

La incapacitación se concibe y se regula en nuestro sistema como una institución restrictiva de la autonomía y de los derechos de la persona incapacitada y precisamente por tal razón se predica de ella un carácter excepcional ${ }^{10}$. Tal restricción se considera, en todo caso, necesaria a la luz del principio de protección en torno al cual se articula el entero sistema de incapacitación y su modelo de sustitución.

En primer lugar, la limitación de la capacidad jurídica y la sustitución en la toma de decisiones se orientan a proteger a la propia persona incapacitada ${ }^{\text {II }}$. Este fundamento claramente proteccionista explica la vis expansiva de la incapacitación que irradia, como luego se verá, en diferentes ámbitos y la opción preferente, en la práctica, por la sustitución total de la persona en todas sus esferas de actuación desde la consideración de que «si se trata sólo de proteger, cuanto más protección, mejor» ${ }^{\mathrm{I2}}$.

Pero, en todo caso, la regulación de la capacidad jurídica en nuestro sistema, y en otros muchos, no se orienta sólo a proteger a la persona «incapacitada», sino también a proteger la integridad, el valor y la utilidad de ciertas prácticas consideradas socialmente relevantes determinando quiénes pueden y quiénes no pueden participar en ellas. En este punto resulta esencial tener en cuenta que en muchas legislaciones nacionales, y también en la legislación española, la capacidad jurídica es regulada en el ámbito de la legislación civil de acuerdo con los principios y necesidades propias del Derecho privado ${ }^{\mathrm{I3}}$. Desde este

9 Vid. sobre este modelo PALACIOS, A., El modelo social de discapacidad, cit., págs. 66 y ss. Una crítica contundente a este modelo puede verse en los trabajos contenidos en BARTON, L., (comp.) Discapacidad $Y$ sociedad, Madrid, Morata, I998.

1o En este sentido, el Tribunal Constitucional en su Sentencia I74/2002, de I9 de octubre, Sala Segunda, señala que «toda restricción o limitación de su capacidad de obrar afecta a la dignidad de la persona y a los derechos inviolables que le son inherentes, así como al libre desarrollo de la personalidad (art. 10.1 CE)»

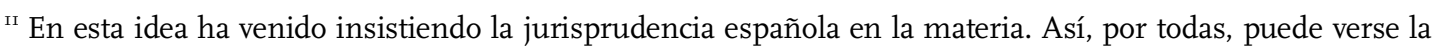
sentencia STS de 3i diciembre I99I, sala de lo civil, RJ I991/9483, en la que se afirma: «ésa y no otra es la finalidad primordial de la incapacitación: la protección de la persona que no se halla en condiciones físicas o psíquicas de protegerse a sí misma». Este aspecto se repite en la STS de 29 abril 2009 ya citada: «Una medida de protección como la incapacitación, independientemente del nombre con el que finalmente el legislador acuerde identificarla, solamente tiene justificación con relación a la protección de la persona»

${ }^{12}$ SEOANE RODRÍGUEZ, J.A. y ÁLVAREZ LATA, N., «El proceso de toma de decisiones de la persona con discapacidad: una revisión de los modelos de representación y guarda a la luz de la Convención sobre los derecho de las personas con discapacidad», Derecho privado y Constitución, núm. 4, 20I0, págs. II-66, pág. 29.

${ }^{13}$ BARIFFI, F., «Capacidad jurídica y capacidad de obrar de las personas con discapacidad a la luz de la Convención de la ONU» en PÉREZ BUENO, L.C. (dir.) y SASTRE, A., (coord.), Hacia un Derecho de la Discapacidad, Estudios en Homenaje a Rafael de Lorenzo, Pamplona, Thomson Reuters Aranzadi, 2009, págs. 353390 , pág. 356. 
enfoque, la capacidad jurídica es abordada básicamente como una cuestión técnica ${ }^{\mathrm{I}}$ relacionada con la intervención en el tráfico jurídico y conforme con el fin básico de proteger la seguridad del mismo. Y, en estas coordenadas, la representación y la administración del patrimonio se presentan como un modelo cómodo. Además, y en relación con lo anterior, el Derecho privado se ha venido mostrando muy poco permeable a los principios -acordes con el modelo social y el discurso de los derechos humanos- que en los últimos años han ido marcando la evolución del tratamiento de la discapacidad en el ámbito del Derecho público ${ }^{\mathrm{IS}}$.

En este sentido, se ha afirmado, con razón, que el modelo de sustitución vigente en la legislación española da prioridad a la protección y a la seguridad jurídica sometiendo, en ocasiones en exceso, la autonomía de las personas con discapacidad ${ }^{16}$.

\section{II.2. Aspectos centrales}

Como es sabido, el sistema español -de inspiración latina en este punto- parte de la distinción entre personalidad jurídica, capacidad jurídica y capacidad de obrar ${ }^{\text {I7 }}$. La primera se identifica con la capacidad de ser reconocido como persona ante la ley, y por tanto, se erige en un requisito previo y en una precondición imprescindible para la adquisición de derechos y deberes ${ }^{18}$. Por su parte la capacidad jurídica se identifica con la posibilidad de ser titular de derechos y deberes ${ }^{\text {I }}$. Se trata de una cualidad pasiva que refleja la idoneidad del individuo para ser receptor de efectos jurídicos ${ }^{20}$. Por su parte, la capacidad de obrar es una cualidad activa que alude a la aptitud de la persona para realizar actos jurídicos de manera directa y válida. Dicho de otro modo, la capacidad de obrar es una cualidad que se predica respecto de la persona cuando ésta es hábil para ejercitar por sí misma sus propios derechos y, en general, para desenvolverse con autonomía en la vida jurídica ${ }^{2 \mathrm{I}}$. Mientras que la capacidad jurídica se posee por el mero hecho de ser persona y no conoce de grados, de modificaciones ni de sustituciones, la capacidad de obrar sí puede

${ }^{14}$ QUINN, G., «An ideas paper on Legal Capacity» Disability, European Foundation Center, Bruselas, 2009, disponible en www.efc.be/Networking/InterestGroupsAndFora/.../EFCGQfinal.doc; fecha de consulta io de noviembre de 2012 .

${ }^{15}$ SEOANE RODRÍGUEZ, J.A. y ÁLVAREZ LATA, N., «El proceso de toma de decisiones de la persona con discapacidad», cit., pág. I3.

${ }^{16}$ Idem, pág. 45.

${ }^{17}$ Vid. entre otros, DE CASTRO, F., Derecho civil de España, T.II, Madrid, Civitas, I984, pág. 3 y págs. 49 y 50 y DÍEZ-PICAZO, L., Sistema de derecho civil. Volumen I, II ${ }^{\mathrm{a}}$ ed., Madrid, Tecnos, 2003. Sobre la temática de la capacidad jurídica y la discapacidad, Vid. SOTO RUIZ, J.J., «El estatus jurídico de las personas con discapacidad en las leyes de cabecera del ordenamiento jurídico privado» en DE LORENZO, R., Y PÉREZ BUENO, L.C., (dirs.), Tratado sobre Discapacidad, Pamplona, Thomson, Aranzadi, 2007, págs. 577-622 y PÉREZ DE ONTIVEROS, C., «La capacidad jurídica y la capacidad de obrar: el artículo i2 de la Convención y sus implicaciones en el Derecho Privado español»,, Capacidad Jurídica y Discapacidad. Un Estudio de Derecho Privado Comparado a la luz de la Convención Internacional sobre los Derechos de las Personas con Discapacidad, Cuaderno de trabajo núm. 7, España: Derecho Común, Congreso Permanente sobre Discapacidad y Derechos Humanos, Cáceres, Aprosuba, 2009, págs.3I-49, disponible en: http://www.convenciondiscapacidad.es/Capacidad.html; fecha de consulta I de noviembre de 2012 .

${ }^{\text {I8 }}$ Según DE CASTRO, F., Derecho Civil de España, cit., pág. 3I la personalidad jurídica es la «cualidad jurídica de ser titular y perteneciente a la comunidad jurídica que corresponde al hombre (como tal)»,

${ }^{19}$ Idem, pág. 46. El artículo 267 del Código civil establece que la personalidad jurídica se adquiere con el nacimiento y se extingue con la muerte de la persona.

${ }^{2 \circ}$ ROVIRA SUEIRO, E., La relevancia de la voluntad de la persona para afrontar su propia discapacidad, Madrid, Ed. Ramón Areces, 2006, pág. I4 siguiendo a RAMOS CHAPARRO, E., Ciudadanía Y Familia: Los Estados Civiles de la Persona, Barcelona, Ed. Cedes, I999.

${ }^{2 \mathrm{I}}$ DE CASTRO, F., Derecho Civil de España, cit., págs. 49 y 50. 
encontrarse sujeta a limitaciones en función de las condiciones personales de $\operatorname{los}_{\text {sujetos }}{ }^{22} \mathrm{y}$ en su ejercicio cabe la sustitución y la representación.

El sistema de incapacitación se orienta, precisamente, a regular cuándo puede restringirse la capacidad de obrar de los individuos, el procedimiento a través del cual debe establecerse tal restricción y las consecuencias que de la misma se derivan.

Es común señalar que el sistema español parte de una presunción general de plena capacidad en relación con todas las personas adultas. Se trata, en todo caso, de una presunción iuris tantum que puede rebatirse cuando concurren ciertas circunstancias legalmente previstas y únicamente en el marco de un proceso judicial. En este sentido, el artículo I99 del Código Civil dispone que «nadie puede ser declarado incapaz sino por sentencia judicial en virtud de las causas establecidas en la Ley» ${ }^{23}$. Las causas de incapacitación aparecen reguladas en el art. 200 del Código civil que establece que «Son causas de incapacitación las enfermedades o deficiencias persistentes de carácter físico o psíquico que impidan a la persona gobernarse por sí misma». Por tanto, la capacidad de obrar puede ser restringida cuando la discapacidad impide a las personas «gobernarse por sí mismas».

En relación con esta previsión se suele insistir en que el sistema de incapacitación previsto en le legislación española no considera la discapacidad, o las deficiencias, por sí mismas, como causa de incapacitación afirmándose que el presupuesto fundamental para que opere este «mecanismo de protección» lo constituye la imposibilidad de autogobierno, esto es, la consecuencia de la enfermedad o deficiencia ${ }^{24}$. Sin embargo, aunque en el sistema español la discapacidad no parece bastar para declarar la incapacidad exigiéndose otro elemento adicional, el impedimento de autogobierno, en realidad es la propia discapacidad, su tipo y su gravedad evaluada conforme a parámetros netamente médicos, el único criterio que parece tenerse en cuenta para determinar su concurrencia. De este modo, la regulación de las causas de incapacitación en la legislación española parece tener la intención y desde luego despliega el efecto de incluir únicamente a las personas con discapacidad.

Igualmente se subraya que, al menos en teoría, desde la reforma introducida por la Ley 13/I983, de 24 de octubre, de reforma del Código Civil en materia de tutela ${ }^{25}$ el sistema español de incapacitación se configura como un sistema gradual y flexible que exige que la limitación de la capacidad se adecue al nivel de autogobierno y a las necesidades concretas de protección de cada individuo. En este sentido, además, las normas procesales de la Ley I/2000 de 7 de enero Enjuiciamiento civil $^{26}$ (en adelante LEC) que regulan el procedimiento de incapacitación exigen al juez la determinación de la extensión y los

${ }^{22}$ Idem, pág. I4.

${ }^{23}$ La jurisprudencia también ha insistido en la importancia que reviste el respeto de las garantías que rodean al procedimiento de incapacitación. Así, por ejemplo, la ya citada Sentencia del Tribunal Constitucional I74/2002, de I9 de octubre establece que «la declaración de incapacitación sólo puede acordarse en Sentencia judicial en virtud de las causas establecidas en la Ley (art. 199 CC), mediante un procedimiento en el que se respeten escrupulosamente los trámites o diligencias que exigía el art. 208 CC (y que en la actualidad se imponen en el vigente art. 759 LECiv) que, en la medida en que van dirigidas a asegurar el pleno conocimiento por el órgano judicial de la existencia y gravedad de las enfermedades o deficiencias persistentes de carácter fisico o psíquico que concurren en el presunto incapaz y que le inhabilitan para gobernarse por sí mismo, que son la causa y fundamento de su incapacitación (arts. 199 Y 200 CC), se erigen en garantías esenciales del proceso de incapacitación».

24 Vid., por ejemplo, COMES MUÑOZ, E. Y ESCALONILLA MORALES, B.M., «Discapacidad y procedimiento de incapacitación» en LAORDEN, J., (dir.), Los derechos de las personas con discapacidad, Vol. I, Aspectos jurídicos, Madrid, CGPJ, 2007, págs. I69-226, págs. I8I y I82 y PÉREZ DE ONTIVEROS, C., «La Capacidad Jurídica y la Capacidad de Obrar. El artículo i2 de la Convención y sus implicaciones en el derecho privado español», Derecho privado y Constitución, núm. 23, 2009, págs. 335- 368.

${ }^{25}$ BOE núm. 256 de 26 de octubre.

${ }^{26}$ BOE núm. 7 de 8 de enero de 2000. 
efectos de la incapacitación ${ }^{27}$ y la práctica de las pruebas pertinentes para garantizar la adecuación de las medidas adoptadas al grado de discernimiento de cada sujeto. Por su parte, en el Código civil se contemplan varias figuras para ejercer la «guarda» y «protección» precisamente, atendiendo a la diversidad de la incapacidad de la persona ${ }^{28}$.

No obstante en su aplicación el sistema español se muestra rígido e inflexible. En efecto, las sentencias de incapacitación, incumpliendo claramente el mandato legal, no suelen contener una determinación detallada de las áreas o los actos sobre los que se proyecta la limitación de la capacidad y responden a fórmulas genéricas y a pronunciamientos estereotipados. Así, la práctica ha llevado a establecer dos grandes grados de incapacitación: I) la incapacitación total, que conlleva el sometimiento a tutela del incapacitado, limitándose en estos casos la sentencia a señalar, con carácter general, que el incapaz queda privado de «capacidad de obrar tanto en su esfera patrimonial como en su esfera personal, actuando el tutor como representante que sustituye a la persona incapaz en la toma de sus decisiones en estos dos ámbitos 2) la incapacitación parcial, que supone el sometimiento a curatela del incapacitado, entendiéndose habitualmente, aunque no se establece expresamente en la regulación civil, que el curador debe asistir al incapacitado en la realización de la generalidad de sus actos de disposición de carácter patrimonial.

En todo caso, y a pesar de su rigidez, en el sistema español junto con la sustitución total en la toma de decisiones, articulada a través de la tutela, se prevé una figura de asistencia, el curador, que se afirma no sustituye la voluntad de la persona, sino que la complementa y encauza ${ }^{29}$.

Ahora bien, aunque la naturaleza restrictiva y excepcional de esta institución debería comportar la solución contraria, esto es la tendencia a primar la incapacitación parcial y la curatela (asistencia), la incapacitación total y la tutela (sustitución) constituyen las respuestas generales que la mayoría de las sentencias ofrecen a la situación de las personas (con discapacidad) que tienen dificultades para autogobernarse. En efecto, la curatela por toda una serie de razones, entre las que destaca su percepción como un mecanismo demasiado blando, su escasa regulación legal, y su consideración -erróneacomo una institución exclusivamente patrimonial es escasamente utilizada ${ }^{30}$. Por tanto, cabe afirmar que la incapacitación termina generando sobreprotección presentándose como una medida desproporcionada que restringe en exceso la autonomía de la persona.

El procedimiento de incapacitación se configura en la normativa española como un procedimiento contradictorio que, como se señaló, se inscribe en el ámbito de la jurisdicción civil. El órgano competente en el procedimiento es el juez del lugar de residencia del presunto incapaz, si bien en los últimos años ha ido proliferando la creación de juzgados especializados. La regulación de este procedimiento pone de relieve que la determinación de la imposibilidad del autogobierno, la valoración de su grado, y la elección del correspondiente sistema de guarda, se basan en criterios netamente médicos y que no se tiene en cuenta de manera suficiente la voluntad y las preferencias de la persona.

Ciertamente, la LEC exige como única prueba pericial de carácter obligatorio que el juez debe tener en cuenta un dictamen médico y el «presunto incapaz» es tratado como

\footnotetext{
${ }^{27}$ Vid. en concreto el artículo 760.

${ }^{28}$ SEOANE RODRÍGUEZ, J.A. y ÁLVAREZ LATA, N., «El proceso de toma de decisiones de la persona con discapacidad», cit., pág.30.

29 GUILARTE MARTÍN-CALERO, C., La curatela en el nuevo sistema de capacidad graduable, Madrid, McGraw-Hill Interamericana de España, I997.

3o SEOANE RODRÍGUEZ, J.A. y ÁLVAREZ LATA, N., «El proceso de toma de decisiones de la persona con discapacidad», cit., págs. 30 y 3I.
} 
un mero objeto del proceso de incapacitación al que el juez tiene el deber de examinar, pero no tiene la obligación de escuchar ${ }^{3 \mathrm{I}}$.

La legislación española regula también un procedimiento de reintegración de la capacidad. En este sentido, el art. 76I de la LEC dispone que «sobrevenidas nuevas circunstancias pueda instarse un nuevo proceso que tenga por objeto dejar sin efecto o modificar el alcance de la incapacitación ya establecida» ${ }^{32}$. Sin embargo, no se prevé la revisión periódica, ni de oficio de las medidas adoptadas inicialmente. Como se ha señalado, este precepto parece estar pensando en un cambio definitivo de las condiciones vigentes al momento de la adopción de las medidas iniciales y no en un control regular de las mismas para ajustarlas a las necesidades de la persona en cada momento.

Por lo que respecta al funcionamiento de las figuras de «guarda y protección» el artículo 267 del Código Civil establece que: «El tutor es el representante legal del menor o incapacitado salvo para aquellos actos que pueda realizar por sí solo, ya sea por disposición expresa de la Ley o de la sentencia de incapacitación». Con carácter general la intervención del tutor se proyecta en la sustitución del consentimiento de la persona incapaz. Puesto que, como ya se dijo, las sentencias no suelen pronunciarse concretamente sobre la extensión de la limitación de la capacidad de obrar la esfera de representación o sustitución del tutor se extiende a la generalidad de los actos de carácter personal y patrimonial con la excepción, como enseguida se comprobará, de lo establecido por la ley en relación con algunos actos considerados personalísimos. Además, en relación con algunos actos de especial incidencia en la esfera personal y patrimonial la legislación impone la necesidad de autorización judicial como regla general para la actuación del tutor. Por su parte la curatela, según antes se señaló, exige la intervención o la asistencia del curador en aquellos actos que el juez señale en la sentencia o en su defecto -que suele ser lo habitual- en los actos que la ley establezca (artículos 286-289 del Código civil).

La legislación española no desarrolla específicamente los criterios que deben presidir la toma de decisiones por parte del tutor. Del artículo 216 del Código civil ${ }^{33}$ cabe inferir que este criterio deberá ser «el beneficio del tutelado». De este modo, el tutor, y también el curador, han de guiarse por el mayor interés del tutelado que «ha de prevalecer sobre otros intereses en juego y, por supuesto, sobre el interés del guardador» ${ }^{34}$. Ahora bien, conviene llamar la atención sobre el hecho de que en el orden jurídico español no existe ninguna disposición que establezca la obligación de oír al «incapaz», ni de actuar

${ }^{31}$ El artículo 759 de la Ley de Enjuiciamiento Civil dispone: «En los procesos de incapacitación, además de las pruebas que se practiquen de conformidad con lo dispuesto en el artículo 752, el tribunal oirá a los parientes más próximos del presunto incapaz, examinará a éste por sí mismo y acordará los dictámenes periciales necesarios o pertinentes en relación con las pretensiones de la demanda y demás medidas previstas por las leyes. Nunca se decidirá sobre la incapacitación sin previo dictamen pericial médico, acordado por el tribunal».

${ }^{22}$ Vid. artículo 76r de la Ley de Enjuiciamiento Civil. «1. La sentencia de incapacitación no impedirá que, sobrevenidas nuevas circunstancias, pueda instarse un nuevo proceso que tenga por objeto dejar sin efecto o modificar el alcance de la incapacitación ya establecida.

2. Corresponde formular la petición para iniciar el proceso a que se refiere el apartado anterior, a las personas mencionadas en el apartado 1 del art. 757, a las que ejercieren cargo tutelar o tuvieran bajo su guarda al incapacitado, al Ministerio Fiscal y al propio incapacitado.

Si se hubiera privado al incapacitado de la capacidad para comparecer en juicio, deberá obtener expresa autorización judicial para actuar en el proceso por sí mismo.

3. En los procesos a que se refiere este artículo se practicarán de oficio las pruebas preceptivas a que se refiere el art. 759, tanto en la primera instancia como, en su caso, en la segunda.

La sentencia que se dicte deberá pronunciarse sobre si procede o no dejar sin efecto la incapacitación, o sobre si deben o no modificarse la extensión y los límites de ésta».

${ }^{33}$ Este artículo prescribe que todas las instituciones de guarda se ejerzan en beneficio del tutelado

${ }^{34}$ ÁLVAREZ LATA, N. y SEOANE, J.A., «El proceso de toma de decisiones de la persona con discapacidad», cit., pág. 36. 
conforme a su voluntad, deseos y preferencias o, al menos, de tenerlos en cuenta, en el funcionamiento de su régimen de guarda, ni siquiera en aquellos supuestos en los que se han de adoptar medidas de especial trascendencia ${ }^{35}$. El sistema español, por ende, no involucra a la persona incapacitada en la toma de sus decisiones ${ }^{36}$.

La única excepción la constituye el caso en el que la persona haya establecido previsiones en relación con una posible incapacitación futura a través de la denominada autotutela. Así de conformidad con el artículo 223 del Código Civil: «Cualquier persona con capacidad de obrar suficiente, en previsión de ser incapacitado judicialmente en el futuro podrá en documento notarial adoptar cualquier disposición relativa a su propia persona y bienes, incluida la designación de tutor». Esta voluntad manifestada por el interesado será vinculante tanto para el juez al constituir la tutela como para el tutor en la toma de sus decisiones salvo que, tal y como dispone el artículo 224 del Código civil, el beneficio del incapacitado exija otra cosa, en cuyo caso, la decisión que se adopte ha de ser motivada. El recurso a la autotutela exige según el tenor del artículo 223 capacidad de obrar suficiente por lo que se plantea la duda de si las personas sometidas a curatela podrían hacer uso de ella ${ }^{37}$.

Por otro lado, importa subrayar que aunque la limitación de la capacidad jurídica y la sustitución en la toma de decisiones afecta no sólo a la esfera económica, sino también a esferas políticas, civiles, ciudadanas y personales, el sistema español de incapacitación se centra en exceso -como consecuencia del tratamiento de la capacidad jurídica desde los principios propios del Derecho civil- en la protección de los aspectos patrimoniales, a los que se refieren la práctica totalidad de los preceptos del Código civil que regulan el funcionamiento de las instituciones de guarda y protección que casi no contienen previsiones relativas a intereses de índole personal del incapacitado y descuidan las demás esferas, lo que puede generar una desprotección de las persona en estos ámbitos.

Ciertamente, la restricción de la capacidad jurídica en el ámbito civil irradia en todo el régimen de ejercicio de los derechos en la medida en que afecta no sólo a la capacidad general para prestar consentimiento en éste y otros ámbitos ${ }^{38}$, sino también a la capacidad procesal ${ }^{39}$, a la capacidad para celebrar contratos de trabajo ${ }^{40}$, a la capacidad para asociarse $^{4 \mathrm{I}}$, a la capacidad para votar etc. que, en el sistema jurídico español -como en otros muchos- se hacen depender de ella. Igualmente, importa resaltar que en relación con

${ }^{35}$ Idem, pág. 37. Se trata de uno de los aspectos que, incluso aquellos autores que, con carácter general, consideran la normativa española sobre capacidad jurídica conforme a la CDPD entienden esencial modificar, Vid. PÉREZ DE ONTIVEROS BAQUERO, C., «La Convención Internacional sobre los Derechos de las Personas con Discapacidad y el sistema español de modificación de la capacidad de obrar», cit., págs. 365 y ss.

${ }^{6}$ ÁLVAREZ LATA, N. y SEOANE, J.A., «El proceso de toma de decisiones de la persona con discapacidad», cit., pág. 36.

37 Como señalan ÁLVAREZ LATA, N. y SEOANE, J.A., «El proceso de toma de decisiones de la persona con discapacidad», cit., pág. 37 nota 47. Estos autores citan en este punto la Sentencia de la Audiencia Provincial de Navarra de I4 junio 2005 (AC 2005/I8I3) que considera que el sometido a curatela es «casi» capaz y que podría designar tutor para el supuesto de incapacitación total siempre que tenga suficiente capacidad natural.

${ }^{38}$ Así, con carácter general establece el artículo I263 del Código civil que los incapaces no pueden prestar consentimiento.

${ }^{39}$ El artículo 7 de la Ley Enjuiciamiento Civil señala que sólo tienen capacidad para comparecer en juicio quienes se hallen en pleno ejercicio de sus derechos civiles, debiendo hacerlo las personas que no cumplan esta condición a través de representante o nombrándose un defensor judicial. Vid. en el mismo sentido el art. I6 de la Ley de Procedimiento Laboral.

${ }^{40}$ Por ejemplo, el artículo 7 Real Decreto Legislativo I/I995, de 24 de marzo, por el que se aprueba el texto refundido de la Ley del Estatuto de los Trabajadores, BOE núm. 75 de 29 de marzo de 1995 establece, de nuevo, que «podrán contratar la prestación de su trabajo quienes tengan plena capacidad de obrar conforme a lo dispuesto en el Código civil».

${ }^{4 \mathrm{I}}$ También para constituir asociaciones y formar parte de las mismas el artículo 3.a) de la Ley Orgánica I/2002 reguladora del derecho de asociación, Boletín Oficial del Estado, núm. 73 de 26 de marzo de 2002, exige tener plena capacidad de obrar. 
ciertos actos en los que está implicado el ejercicio de los derechos fundamentales la legislación española prevé determinadas incapacidades específicas que también descalifican a las personas con discapacidad ${ }^{42}$.

Por lo que respecta al ejercicio de los denominados derechos «personalísimos», entre los que se encuentran algunos derechos fundamentales, se ha extendido la consideración de que en este ámbito no se proyecta directamente la incapacitación ni tiene cabida la sustitución en la toma de decisiones. En este sentido, se defiende que para el válido ejercicio de tales derechos bastaría con que su titular posea lo que se denomina «capacidad natural» definida como la capacidad de entendimiento y juicio suficientes para comprender, dada una determinada situación, el alcance y las consecuencias de la decisión a adoptar ${ }^{43}$. De este modo, se sostiene que el incapacitado, con independencia de que esté sometido a tutela o a curatela, siempre que tenga suficiente capacidad natural podrá ejercer sus derechos fundamentales y personalísimos y que de no poseer dicha capacidad se afirma que nadie podrá ejercer estos derechos por é ${ }^{44}$.

Pues bien, en relación con esta cuestión considero pertinente realizar tres órdenes de consideraciones. En primer lugar, conviene tener presente que la determinación de la capacidad natural se hace depender de la «competencia mental» y se evalúa, de nuevo, conforme a criterios estrictamente médicos por lo que, otra vez, su exigencia resulta excluyente para las personas con discapacidad. En segundo lugar, importa señalar que, en todo caso, la sustitución en la toma de decisiones se permite en el sistema español en relación con actos tan «personalísimos» como la esterilización, el internamiento, o los tratamientos médicos. En tercer lugar, interesa subrayar que si bien la consideración de que los mecanismos de sustitución no se proyectan, con algunas excepciones, en ámbitos vinculados con el ejercicio de derechos fundamentales trata de ser más respetuosa con la autonomía de las personas con discapacidad, plantea también problemas evidentes. Y es que la prohibición de la sustitución en estos ámbitos, sin que se prevean otras medidas orientadas a superar los obstáculos que las personas con discapacidad pueden encontrar para el ejercicio de su llamada «capacidad natural», puede redundar en su exclusión total de unas esferas de actuación consideradas esenciales ${ }^{45}$.

${ }^{42}$ Por ejemplo, el artículo I82 del Reglamento Notarial establece que «Son incapaces o inhábiles para intervenir como testigos en la escritura: $1 .^{\circ}$ Las personas con discapacidad psíquica, los invidentes, los sordos y los mudos» El artículo 8 de la Ley 5/I995, de 22 de mayo, del Tribunal del Jurado, BOE núm. I22 de 23 de mayo de I995, establece como requisito para ser jurado «No estar impedido física, psíquica o sensorialmente para el desempeño de la función de Jurado».

43 SANTOS MORON, M.J., Incapacitados $y$ derechos de la personalidad: tratamientos médicos: honor, intimidad e imagen, Madrid, Escuela Libre, 2000.

${ }^{44}$ Cabe matizar que esta opinión es contestada por parte de la doctrina que defiende la posibilidad y conveniencia de suplir a las personas incapacitadas o carentes de capacidad natural en el ejercicio de sus derechos fundamentales siempre y cuando «la facultad de cuyo heteroejercicio se trate permita satisfacer su interés iusfundamental», BASTIDA FREIJEDO, F.J. y otros, Teoría General de los Derechos Fundamentales en la Constitución Española de 1978, Madrid, Tecnos, 2004. En esta línea se ha pronunciado la STS 3II/2000 de I8 de diciembre, RTC $2000 / 3 \mathrm{I} 3$, en relación con la legitimación del tutor para el ejercicio de la de la acción de separación que el tribunal de instancia había denegado por afectar a un derecho personalísimo.

${ }^{45}$ A este problema alude C. PÉREZ DE ONTIVEROS en su trabajo «La Convención Internacional sobre los Derechos de las Personas con Discapacidad y el sistema español de modificación de la capacidad de obrar», ya citado, pág. 364. La autora considera que las medidas sustitutivas -que, a su juicio, no están totalmente excluidas por la CIDPD- no deben incidir en las cuestiones relacionadas con los derechos fundamentales cuando las personas a ellas sometidas tengan suficiente capacidad natural, pero no deja de apuntar que la Convención obliga a «reflexionar acerca del establecimiento de mecanismos más flexibles de actuación que potenciaran la posible capacidad residual de la persona incapacitada». 


\section{El sistema de apoyo en la toma de decisiones en la Convención Internacional sobre los Derechos de las Personas con Discapacidad}

En este apartado expondré los elementos esenciales del sistema de apoyo al ejercicio de la capacidad jurídica por el que aboga el artículo i2 de la CDPD. De nuevo, al igual que en la exposición del sistema de sustitución vigente en el sistema español, dividiré la exposición en la presentación de sus principios inspiradores y el análisis de sus aspectos básicos.

\section{III.I. Principios generales}

El nuevo sistema de apoyo en la toma de decisiones se inspira en un enfoque y en unos principios claramente alejados de los parámetros que guían la regulación actual de la capacidad jurídica en el sistema español.

Así, en primer lugar, aborda la cuestión de la capacidad jurídica desde los presupuestos del denominado modelo socia ${ }^{46}$. Este modelo entiende que la discapacidad está originada no tanto por las limitaciones personales ocasionadas por el padecimiento de una deficiencia -como sostiene el modelo médico- sino por las limitaciones de una sociedad que no tiene presente en su diseño la situación de la personas con discapacidad generando barreras que las excluyen y discriminan. De este modo, no son las personas con discapacidad las que tienen que adaptarse y rehabilitarse para poder participar plenamente en la vida social, sino que es la sociedad la que debe re-diseñarse para garantizar su inclusión en igualdad de condiciones. Esta visión, que impregna la totalidad del texto de la CDPD, se plasma claramente en la definición de personas con discapacidad. Así, en el Preámbulo de la Convención se afirma que «la discapacidad es un concepto que evoluciona $y$ que resulta de la interacción entre las personas con deficiencias y las barreras debidas a la actitud $y$ al entorno que evitan su participación plena y efectiva en la sociedad, en igualdad de condiciones con las demás» y en el artículo I se señala que «las personas con discapacidad incluyen a aquellas que tengan deficiencias físicas, mentales, intelectuales o sensoriales a largo plazo que, al interactuar con diversas barreras, puedan impedir su participación plena y efectiva en la sociedad, en igualdad de condiciones con las demás». Y el modelo social se deja sentir también de manera nítida en la regulación de la capacidad jurídica.

Desde el enfoque propio del modelo social esta regulación parte de la consideración de que las dificultades que las personas con discapacidad pueden tener para tomar sus propias decisiones pueden estar ocasionadas y desde luego verse agravadas por la manera en la que hemos diseñado nuestro entorno (intelectual, comunicacional). Asumiendo esta visión, el artículo i2 se centra en la eliminación de barreras y en la adaptación de las condiciones de ejercicio de la capacidad jurídica a la situación y a las necesidades de las personas con discapacidad. La capacidad jurídica es una construcción social que debe rediseñarse para incluir a las personas con discapacidad. Ya no se trata de detectar los déficits que impiden el ejercicio de la capacidad y justifican la sustitución por un tercero en la toma de decisiones. De lo que se trata es de analizar la situación de la persona y establecer las medidas necesarias -que pueden consistir en el apoyo de un tercero- para que pueda ejercer su capacidad jurídica en igualdad de condiciones con los demás.

En conexión con la asunción del modelo social, la CPDD impone el reemplazo del punto de vista asistencialista y del enfoque iusprivatista por la perspectiva de los derechos humanos. A mi modo de ver, en su proyección concreta en el ámbito de la capacidad jurídica este cambio posee dos dimensiones, estrechamente relacionadas. En primer lugar implica que la cuestión de la capacidad jurídica de las personas con discapacidad debe ser

\footnotetext{
${ }^{46}$ Vid. sobre este modelo, PALACIOS, A., El modelo social de discapacidad, ya citado.
} 
abordada de manera prioritaria desde los valores, principios y fines básicos que presiden el discurso de los derechos humanos que ha de permear también, de una vez por todas, el Derecho privado. Y, en segundo lugar, y en conexión con lo anterior, pone de relieve que el reconocimiento de la capacidad jurídica constituye no sólo una condición necesaria para la válida intervención en el tráfico jurídico, sino también y sobre todo un requisito imprescindible para el ejercicio de todos los derechos humanos.

Por lo que respecta a la primera de las consideraciones apuntadas, la autonomía, esto es, la idea de que cada uno puede elegir libremente sus metas y dar los pasos más adecuados para conseguirlas, ostenta un carácter central en todo el texto de la Convención La autonomía y la libertad para tomar las propias decisiones, intrínsecamente vinculadas la proclamación de la dignidad inherente de las personas con discapacidad, aparecen mencionadas como principios generales en el artículo 3 de la CDPD e inspiran la regulación de la capacidad jurídica contenida en el artículo I2. Estos principios requieren, en un sentido negativo, el respeto de la libre elección de planes vida que no puede verse restringida por razón de discapacidad. Y, en un sentido positivo, reclaman que en aquellas situaciones en las que las diferencias que, en efecto, algunas personas puedan tener en sus capacidades cognitivas puedan generar dificultades en la toma de decisiones se adopten las medidas o instrumentos pertinentes para eliminarlas o paliarlas, entre los que, de nuevo, las medidas de apoyo adquieren un papel de primer orden ${ }^{47}$. El objetivo, por ende, es promover y maximizar la autonomía de las personas con discapacidad y no negarla, entorpecerla o impedirla, esgrimiendo como fundamento incuestionable el principio de protección. Así, el artículo I2 impone un nuevo balance entre el principio de protección y el principio de autonomía.

También el principio de participación plena e inclusión en la vida social, mencionado asimismo en el artículo 3 de la CDPD y presente a lo largo de todo su articulado, se plasma claramente en las previsiones del artículo I2. En este ámbito dicho principio implica la participación de las personas con discapacidad en la toma de todas las decisiones que les afecten en «todos los aspectos de la vida». A diferencia del sistema de sustitución, el sistema de apoyo garantiza esta participación. Dicha garantía se concreta, además, en la exigencia de respetar en el funcionamiento de este sistema la voluntad y preferencias de las personas con discapacidad, contemplada como una de las salvaguardas a las que alude el apartado 4 del artículo I2.

Del mismo modo que sucede en la regulación de otros derechos, también el artículo I2 de la CDPD es el resultado de la interactuación del principio de igualdad y no discriminación con el derecho al ejercicio de la capacidad jurídica. En efecto, este precepto identifica contenidos adicionales, necesidades extra, medidas instrumentales y garantías específicas -medidas de apoyo, salvaguardas- para asegurar que las personas con discapacidad puedan acceder al ejercicio de la capacidad jurídica en igualdad de condiciones con las demás y sin discriminación alguna. En este punto el artículo i2 conecta con el artículo 5 de la CDPD que prohíbe la discriminación por motivos de discapacidad definida en el artículo 2 como «cualquier distinción, exclusión o restricción por motivos de discapacidad que tenga el propósito o el efecto de obstaculizar o dejar sin efecto el reconocimiento, goce o ejercicio, en condiciones de igualdad, de todos los derechos humanos y libertades fundamentales en los ámbitos político, económico, social, cultural, civil o de otro tipo».

La accesibilidad universal y los ajustes razonables -como contenidos implícitos del principio de igualdad y herramientas esenciales del modelo social- adquieren una

47 ASÍS ROIG, R. DE, «La incursión de la discapacidad en la teoría de los derechos: posibilidad, elección, Derecho y Poder» en CAMPOY CERVERA, I., (ed.), Los derechos de las personas con discapacidad: perspectivas sociales, políticas, jurídicas y filosóficas, Madrid, Dykinson, 2004, págs. 59-73, pág. 67. 
relevancia central en la cuestión del ejercicio de la capacidad jurídica ${ }^{4}$. El reconocimiento de la igualdad en la capacidad jurídica de las personas con discapacidad requiere, en efecto, que se cumplan las exigencias de accesibilidad en todos los ámbitos en los que debe ejercerse la capacidad jurídica y donde las dificultades persisten, no se trata de transferir el derecho a decidir a un tercero, sino de poner a disposición de las personas los ajustes y apoyos individualizados necesarios ${ }^{49}$ para que la persona pueda tomar sus propias decisiones.

Por lo que respecta a la segunda de las consideraciones realizadas, importa señalar que el reconocimiento de la capacidad jurídica constituye la puerta de acceso al discurso jurídico ${ }^{50} \mathrm{y}$ al ejercicio de todos los derechos ${ }^{5 \mathrm{I}}$. En este sentido, se ha destacado el valor instrumental del artículo i2 para el disfrute de todos los derechos reconocidos en la $\mathrm{CDPD}^{52}$ y por tanto también en las legislaciones internas. De este modo el reemplazo del sistema de sustitución por el sistema de apoyo en la toma de decisiones resulta crucial para la plena materialización del cambio de paradigma que la Convención impone en el tratamiento de la discapacidad, esto es, el paso de la consideración de las personas con discapacidad como objetos de cuidado, de tratamiento médico y de atención a su contemplación como auténticos sujetos de derechos capaces de ejercerlos por sí mismos, con la asistencia adecuada.

\section{III.2. Aspectos centrales}

Como antes se indicó el sistema de sustitución en la toma de decisiones se erige en una pieza central en la configuración tradicional de los sistemas de incapacitación. Por su parte, el sistema de apoyo en la toma de decisiones constituye un pilar imprescindible para garantizar a las personas con discapacidad la igualdad en el ejercicio de su capacidad jurídica reconocida en el artículo I2.2 y, con ello, la igualdad en el ejercicio de los derechos. En este punto, conviene aclarar que el artículo I2.2 engloba, tal y como se ha defendido desde diversos ámbitos con argumentos convincentes, tanto la capacidad jurídica como la capacidad de obrar ${ }^{53}$.

Esta garantía de igualdad exige, en primer lugar, reconocer una presunción de capacidad a favor de las personas con discapacidad. La capacidad jurídica de estas personas

\footnotetext{
${ }^{48}$ ASÍS ROIG, R. DE, «Sobre la capacidad» en BARIFFI, F. Y PALACIOS, A., (coords.), Capacidad Jurídica, Discapacidad y Derechos Humanos: una revisión desde la Convención Internacional sobre los Derechos de las Personas con Discapacidad, Buenos Aires, Ediar, 2012, págs. 13-29.
}

49 International Disability Alliance, «Principios para la implementación del artículo I2 de la CDPD» disponible en http://www.internationaldisabilityalliance.org; fecha de consulta 25 de noviembre de 2012.

$5^{\circ}$ ASÍS ROIG, R. DE, «Sobre la capacidad», cit., pág. I4

${ }^{5}$ BARIFFI, F., «Capacidad jurídica y capacidad de obrar de las personas con discapacidad a la luz de la Convención de la ONU», cit., pág. 357.

52 «Estudio temático preparado por la Oficina del Alto Comisionado de las Naciones Unidas para los Derechos Humanos para mejorar el conocimiento y la comprensión de la Convención sobre los derechos de las personas con discapacidad», A/HRC/IO/48 de 26 de enero de 2009 , disponible en español en http://www2.ohchr.org/english/issues/disability/docs/A.HRC.IO-48_sp.doc; fecha de consulta 20 de octubre de 2012.

53 Esta interpretación puede apoyarse en el informe que el Alto Comisionado de Naciones Unidas para los Derechos Humanos presentó al Comité Especial en su Sexta Reunión denominado «Capacidad jurídica», «Informe presentado por el Alto Comisionado para los Derechos Humanos de Naciones Unidas sobre Capacidad Jurídica» para la Sexta reunión del Comité Especial de la Convención sobre discapacidad, http://www.un.org/esa/socdev/enable/rights/documents/ahc6ohchrlegalcap.doc, fecha de consulta io de septiembre de 20II. También en el resto de los incisos del artículo i2 y en el conjunto del texto de la Convención, en su espíritu, en su finalidad y en la existencia de reservas a este precepto, de dudosa admisibilidad. 
se debe siempre presumir, lo que significa una relevante inversión de la carga de la prueba respecto de la regulación y/o de la aplicación práctica de muchas legislaciones nacionales. La CDPD impide, además, que la discapacidad o las deficiencias por sí mismas puedan constituir excepciones justificadas a esta presunción general de plena capacidad jurídica.

Estas exigencias irrenunciables implican la necesidad de derogar todas las previsiones que permiten derrumbar la presunción de capacidad basándose directa o indirectamente (como sucede en el sistema español) en la discapacidad o las deficiencias y requieren, consecuentemente, que en la evaluación de la capacidad y en la determinación de las medidas que incidan en este ámbito se tome en consideración la situación global de la persona -los factores individuales y contextuales- y no únicamente el diagnóstico clínico.

En un sentido mínimo la presunción de capacidad jurídica requiere, además, articular como primera alternativa un sistema de apoyo en la toma de decisiones que favorezca su conservación y su ejercicio por la propia persona convirtiendo en una auténtica excepción la institución de la incapacitación y los mecanismos de sustitución que, en todo caso, deberán establecerse con carácter puntual y revisable y no de manera abstracta, general y permanente y nunca por razón de discapacidad. Esta lectura de mínimos del artículo I2 exigiría ya importantes reformas de la legislación española.

Desde una lectura de máximos, a mi modo de ver más ajustada al espíritu de la Convención, la capacidad jurídica se configuraría como un atributo universal que no se puede limitar si bien podría admitir diferentes modalidades de ejercicio. De acuerdo con esta interpretación la presunción de capacidad jurídica establecida por el artículo I2.2 se presenta como un principio general que no admite excepciones, como una presunción iuris et de iure, y el sistema de apoyo reemplaza completamente al sistema de sustitución, lo que supone no ya la necesidad de reformar y complementar los sistemas de incapacitación y de sustitución vigentes, sino que implica su total desmantelamiento. Esta visión reclamaría, por tanto, una reforma más profunda y radical de la legislación española.

Asumir esta interpretación más «revolucionaria» no supone negar la evidencia de que en algunas situaciones -por ejemplo, en aquellas circunstancias en las que no es posible por ningún medio conocer la voluntad de la persona- la necesidad de apoyo será tan intensa que consistirá en la práctica en una «acción de sustitución». En todo caso, la acción de sustitución, cuya pertinencia deberá ser evaluada en cada caso, se llevaría a cabo en función de la concurrencia de una situación determinada y, en consecuencia, podría tener cabida en situaciones que no son de discapacidad. Además, esta acción de sustitución deberá realizarse desde el paradigma del modelo de apoyo y, por tanto, tendrá que ser coherente con la narrativa y la historia de vida de la persona con discapacidad, con sus preferencias, valores, deseos etc.

Sea cual sea la lectura por la que nos decantemos, resulta claro que el inciso 3 del art. I2 establece, en aras de asegurar en la práctica la igualdad reconocida en su inciso 2, la obligación de los Estados de articular los apoyos que las personas con discapacidad puedan requerir en el ejercicio de su capacidad jurídica.

Al igual que sucede en los sistemas de sustitución, también en el sistema de apoyo interviene un tercero en la toma de decisiones de la persona pero su papel es sustancialmente distinto: no se trata de decidir por la persona, sustituyendo su voluntad, sino que se trata de ayudar a decidir a la persona por sí misma. Las medidas de apoyo, a diferencia de los mecanismos de sustitución, no deben contemplarse como medidas restrictivas sino como medidas promocionales de la autonomía y de la capacidad que tratan de potenciar al máximo las posibilidades de ejercicio de los derechos.

Conviene también insistir en que la necesidad de apoyo y su intensidad, en el marco de la filosofía de la Convención, deben evaluarse atendiendo no sólo a parámetros 
médicos, ni a habilidades funcionales, sino también a factores sociales y lo mismo cabe afirmar en relación con la modalidad, el nivel y la figura de apoyo considerada pertinente.

La CDPD no diseña específicamente el sistema de apoyo dejándolo abierto a las legislaciones nacionales ${ }^{54}$. En todo caso, y de una lectura de conjunto de la CDPD es posible inferir algunas características y rasgos generales que debería cumplir este sistema ${ }^{55}$.

En primer lugar, el sistema de apoyo debe ser implantado de manera gradual y paulatina por lo que posiblemente durante un tiempo deberá convivir en paralelo con el sistema de sustitución. Y, en mi opinión, ha de diseñarse de un modo abierto e inclusivo dando cabida a todas las personas que puedan tener dificultades para ejercer su capacidad jurídica y no sólo a las que tienen un determinado tipo de discapacidad. También las personas sin discapacidad podrían en ciertas situaciones beneficiarse de este sistema.

El sistema de apoyo debe ser complejo. En este sentido, resulta imprescindible aclarar que su articulación no puede consistir simplemente en reemplazar el nombre de tutela o curatela por el de persona de apoyo en las legislaciones nacionales, sino que exige crear y/o promover la creación de diversas figuras de apoyo y dotarlas de un estatus legal, adaptar o reemplazar otras instituciones legales, establecer protocolos que favorezcan la prevención de ciertas situaciones, desarrollar una acción política que garantice la capacitación de las personas con discapacidad y de las personas de apoyo, dotar de recursos materiales, humanos y financieros etc. El funcionamiento adecuado de este sistema debe involucrar, además, a toda la sociedad. El Estado y sus diferentes autoridades y funcionarios (no sólo jueces y fiscales, sino también médicos, notarios etc.) deben velar por el buen funcionamiento del sistema de apoyo y también diferentes agentes y operadores privados de diferentes áreas deben contribuir.

El sistema de apoyo debe ser diverso, individualizado y centrado en las necesidades de la persona adaptándose a las diferentes situaciones personales y sociales teniendo en cuenta, entre otras circunstancias, el tipo de figura de apoyo y el tipo de acto jurídico implicado. Las medidas de apoyo deben cubrir todo el proceso de toma de decisiones pudiendo consistir, en función de cada situación, en la asistencia para la traslación, comprensión y/o evaluación de información relevante, valoración de las diferentes opciones y sus consecuencias, expresión de voluntad y preferencias etc. El sistema de apoyo debe ser diseñado como un «continuum», contemplando apoyos más o menos intensos. Los apoyos más intensos, como antes se señaló, pueden llegar a consistir en la práctica en decidir por la persona y no con la persona. Pero no se trata de una sustitución en la toma de decisiones similar a la existente en los sistemas de incapacitación. En primer lugar, porque a la luz del art. i2 estas situaciones se convierten realmente en situaciones extremas y excepcionales y en muchos casos reversibles a través del fomento de relaciones de comunicación significativas y de confianza. En segundo lugar, porque según ya se dijo, las acciones de sustitución no pueden justificarse en la discapacidad de la persona y por tanto pueden tener cabida en las situaciones que no son discapacidad. En tercer lugar, porque la acción de sustitución sólo puede tener lugar en relación con decisiones que necesitan ser adoptadas y que no supongan un daño irreparable a la persona o sus derechos. Y, sobre todo, porque, como también se indicó, deben respetar la identidad, historia de vida etc. de la persona afectada.

${ }^{54}$ En todo caso, en el diseño de este modelo se deberá dar participación a las personas con discapacidad en cumplimiento de la obligación establecida en el art. 4.3 de la CDPD.

${ }^{55}$ Sobre los rasgos generales que debe cumplir el sistema de apoyo en la toma de decisiones a la luz de la Convención Vid. PALACIOS, A., «Consultative meeting with stakeholders on legal measures key for the ratification and effective implementation of the CRPD » (ponencia presentada en el marco del Estudio del Alto Comisionado de las Naciones Unidas para los Derechos Humanos sobre medidas jurídicas esenciales para la ratificación y la aplicación efectiva de la Convención sobre los Derechos de las Personas con Discapacidad, Geneva, 24 October 2008) y BARIFFI, F., «Capacidad juridica y capacidad de obrar a la luz de la Convención de la ONU», cit., pág. 383 y ss. 
A mi modo de ver, el sistema de apoyo ha de basarse en el reconocimiento y valoración de los apoyos informales con los que cuentan las personas que tienen dificultades en la toma de sus decisiones y permitir e incluso fomentar $u$ obligar, en algunas situaciones, a la formalización de estos apoyos. En todo caso, la ausencia de formalización no puede ser nunca una excusa para denegar el reconocimiento y la prestación de los apoyos.

Las medidas de apoyo deben caracterizarse por su amplitud y, por tanto, proyectarse en todas aquellas esferas en las que las personas requieran apoyo en la toma de sus decisiones y mantenerse -con las debidas revisiones- mientras sean necesarias. En todo caso, el funcionamiento de estas medidas y la articulación de todo el sistema debe estar presidido por los derechos. Ello implica que el sistema de apoyo no sólo debe ser respetuoso con los derechos, sino orientarse de modo prioritario a favorecer el ejercicio de los derechos por parte de las personas a las que se dirige. Por tanto, los mecanismos de apoyo -en contra de lo defendido desde algunos planteamientos- deben proyectarse sobre cuestiones relacionadas con el ejercicio de derechos fundamentales. En todo caso, y dada la relevancia de la materia afectada, deben establecerse especialmente en este ámbito garantías adecuadas.

Finalmente, el sistema de apoyo debe estar «salvaguardo», exigencia a la que se refiere, precisamente, el apartado 4 del art. I2.

Algunos planteamientos conciben estas salvaguardas como medidas para el ejercicio de la capacidad jurídica diferentes y más fuertes que los apoyos, lo que podría abrir la puerta al modelo de sustitución, tal y como se manejó en versiones anteriores de esta disposición. Sin embargo, a tenor de la redacción final del art. I2 y de acuerdo con el espíritu general de la CDPD, debe entenderse que las salvaguardas se proyectan sobre los mecanismos de apoyo, orientándose a evitar los abusos. Las salvaguardas no deben ser contempladas como elementos orientados a regularizar y a racionalizar el modelo de sustitución, sino que su papel es, precisamente, evitar que los mecanismos de apoyo se conviertan en mecanismos de sustitución.

Aunque las salvaguardas deberán concretarse en la implementación del sistema de apoyo, la Convención identifica una serie de ámbitos donde apuntar que respeten los derechos, la voluntad y las preferencias de las personas; que no haya conflicto de intereses ni influencia indebida; que sean proporcionales y adaptadas a las circunstancias de la persona; que se apliquen en el plazo más corto posible que estén sujetas a exámenes periódicos, por parte de una autoridad o un órgano judicial competente, independiente e imparcial; que sean proporcionales al grado en que dichas medidas afecten a los derechos e intereses de las personas.

La referencia al respeto a la voluntad y las preferencias de la persona, antes destacada, ostenta una importancia esencial, y sustituye al criterio «del mejor interés» como parámetro objetivo desde el que decidir por la persona incapacitada. Así, en el funcionamiento general $u$ ordinario de las medidas de apoyo la voluntad y preferencias «subjetivas» siempre deben ser respetadas. En los casos excepcionales de apoyos intensos que puedan llegar a implicar decisiones sustitutivas, los apoyos deberán tratar de «reconstruir» la voluntad y las preferencias de la persona.

\section{La implementación del sistema de apoyo en la legislación española. Algunas propuestas}

Una vez expuestos los principios inspiradores y los rasgos generales del sistema de apoyo presentaré en lo que sigue una propuesta concreta de articulación de dicho sistema en el Ordenamiento jurídico español. Según he venido advirtiendo y tal y como se 
desprende de algunas de las reflexiones desarrolladas en los anteriores apartados, la implementación de la exigencia de igualdad en la capacidad jurídica y del sistema de apoyo en la toma de decisiones no atañe en exclusiva a la legislación civil sino que se proyecta en toda una serie de ámbitos normativos diversos. Obviamente excede con mucho de las pretensiones y del espacio de un trabajo de estas características presentar exhaustivamente todas las dimensiones de la reforma que es necesario llevar a cabo para adaptar nuestro sistema a las exigencias del artículo i2 de la CDPD. Por ello me limitaré a delinear de manera sucinta los aspectos esenciales de las adaptaciones normativas que considero más relevantes ${ }^{56}$.

Es posible sistematizar los cambios normativos que impone el artículo i2 de la CDPD en el sistema español en tres grandes grupos: cambios que afectan a la normativa básica reguladora de los derechos de las personas con discapacidad, cambios que afectan al régimen general de capacidad jurídica, cambios derivados de la irradiación de las reformas anteriores que afectan a las condiciones de realización de diversos actos con trascendencia jurídica y al ejercicio de diferentes derechos.

IV.I. Cambios en la normativa básica sobre los derechos de las personas con discapacidad.

La adaptación normativa al artículo I2 de la CDPD parte de la necesidad de reformular las políticas públicas haciéndolas partícipes del modelo social de tratamiento de la discapacidad e introduciendo el eje accesibilidad, ajustes razonables y apoyos, de prohibir de manera expresa de discriminación por motivo de discapacidad y de asumir de manera completa y decidida la definición de personas con discapacidad que maneja la Convención.

Las dos primeras consideraciones implican la reforma de dos normas constitucionales la relativa al principio de igualdad (artículo I4 CE), introduciendo la referencia explícita a la prohibición de discriminación por motivo de discapacidad que no aparece expresamente mencionada en este precepto, si bien se entiende incluida en la cláusula abierta «cualquier otra circunstancia personal o social» ${ }^{57}$ y la relativa a las políticas en materia de discapacidad (artículo 49 CE) sustituyendo el término «disminuidos» y cambiando el enfoque médico de estas políticas («tratamiento», «rehabilitación», «atención», etc.) por el enfoque social («políticas de inclusión», «autonomía», «establecimiento de condiciones materiales necesarias», etc.), en los términos de la CDPD. Se considera, igualmente, conveniente, introducir en este precepto la referencia expresa a la accesibilidad universal, los ajustes razonables y los apoyos ${ }^{58}$.

${ }^{56}$ En el Informe «Capacidad jurídica y discapacidad. Propuestas para la adaptación normativa del ordenamiento jurídico español al artículo i2 de la CDPD» puede encontrarse un desarrollo detallado de las propuestas de reforma a las que aludiré en este apartado. Este informe está disponible en http://www.uc3m.es/portal/page/portal/instituto_derechos_humanos/sala_prensa/comunicados_de_prensa/inf orme_23/informe_23.pdf; fecha de consulta I de octubre de 20I2. Tuve la oportunidad de exponer algunas de estas propuestas, así como los rasgos generales del modelo de apoyo analizados en el anterior apartado en el Seminario Permanente del Departamento de Derecho de la Universidad de La Rioja. Agradezco a su director, Raúl Susín la invitación a participar en este evento.

${ }^{57}$ Así lo consideró expresamente el Tribunal Constitucional en la Sentencia 269/1994 de 3 de octubre RTC/1994/269.

${ }^{8}$ Se propone la siguiente redacción del artículo 49 de la Constitución española: «Los poderes públicos realizarán una política de integración de las personas con discapacidad, promoviendo la autonomía personal $y$ procurando atención a aquéllas que se encuentren en situación de dependencia. Las políticas públicas de discapacidad deben orientarse al disfrute real $y$ efectivo por parte de las personas con discapacidad de los derechos reconocidos en el presente título, asegurando las exigencias de accesibilidad universal, la realización de ajustes razonables y el uso, reconocimiento y prestación de medidas de apoyo con el objetivo de lograr su inclusión plena y efectiva en la sociedad en igualdad de condiciones con las demás» En todo caso, es posible una lectura del artículo 49 a la luz del modelo social asumido en la Convención, Vid. en este sentido el trabajo de CAMPOY CERVERA, I., «La discapacidad y 
La tercera de las consideraciones apuntadas implica, además, la necesidad de reformar la definición de personas con discapacidad que se recoge en la Ley 13/82 de Integración Social de los Minusválidos ${ }^{59}$ y en la Ley 5I/2003 de Igualdad de Oportunidades, No Discriminación y Accesibilidad Universal ${ }^{60}$ (en adelante, LIONDAU) para asumir sin matices el concepto manejado en la Convención. La definición general de personas con discapacidad, al menos a los efectos de diseñar el alcance de la protección antidiscriminatoria, debe desterrar definitivamente la apelación al criterio del reconocimiento administrativo de un cierto grado de discapacidad ${ }^{6 \text { I }}$. En su caso, cuando el grado de discapacidad pueda ser relevante en relación con algunas cuestiones, por ejemplo en relación con el acceso a prestaciones, se deberá dar más peso a los factores sociales en su baremación ${ }^{62}$.

Por otro lado, resulta imprescindible la modificación de algunas previsiones de la Ley 39/2006 de I4 de diciembre, de Promoción de la Autonomía Personal y Atención a las Personas en Situación de Dependencia ${ }^{63}$ apostando, de nuevo, por introducir los factores sociales tanto en la definición de las situaciones de dependencia y en su valoración, como en las respuestas y medidas diseñadas por la ley, que no deben centrarse únicamente en la persona sino también en el entorno ${ }^{64}$. Además, se considera esencial que esta norma se ajuste a la exigencia de igualdad en el ejercicio de la capacidad jurídica y que se establezcan las medidas de apoyo necesarias para que todas las personas puedan ejercer por sí mismas los derechos en ella reconocidos. Lo mismo cabe afirmar en relación con la Ley 27/2007 de 23 de octubre por la que se reconocen las lenguas de signos españolas y se regulan los

su tratamiento conforme a la Constitución española de I978» en CAMPOY, I. y PALACIOS, A. (eds.), Igualdad, No Discriminación y Discapacidad. Una visión integradora de las realidades española y argentina, Madrid, Dykinson, 2007, págs. $145-207$.

59 BOE núm. I03 de 30 de abril de I982.

6o BOE núm. 289 de 3 de abril de 2003.

${ }^{6 r}$ Sobre la incompatibilidad de la definición de personas con discapacidad que manejaba la LIONDAU en su redacción original con la CDPD que no se ha corregido plenamente en la reforma operada por la Ley de adaptación normativa a la Convención Internacional sobre los derechos de las personas con discapacidad de i de agosto de 20II, Vid. PALACIOS, A., El modelo social de discapacidad, cit., págs. 282 y 283 y « ¿ Modelo rehabilitador o modelo social?» en CAMPOY CERVERA, I. Y PALACIOS, A., (coords.), Igualdad No Discriminación $y$ Discapacidad. Una visión integradora de las realidades española y argentina, Madrid, Dykinson, 2007, págs. 243-305, pág. 304; PALACIOS, A. Y BARIFFI, F., La discapacidad como una cuestión de derechos humanos. Una aproximación a la Convención Internacional sobre los derechos de las personas con discapacidad, Madrid, Cinca, Colección Telefónica Accesible, 2007, págs. 66 y ss.; ASÍS ROIG, R. DE y otros, Sobre la accesibilidad universal en el Derecho, Cuadernos del Instituto de Derechos Humanos Bartolomé de las Casas, Madrid, Dykinson, 2007, págs. 3I y 32; DE LORENZO, R. DE Y CABRA, M.A., «Análisis de la nueva legislación sobre no discriminación, acción positiva y accesibilidad universal» en DE LORENZO GARCÍA, R. Y PÉREZ BUENO, L.C, Tratado sobre discapacidad, cit. págs. 65I-697, pág. 678 y el Informe Alternativo España 2010 realizado por el CERMI disponible en

http://www.cermi.es/es-ES/Novedades\%2oe\%2oinformaci\%C3\%B3n\%2ode\%2ointeres/Paginas/

Inicio.aspx?TSMEIdPub=II97

fecha de consulta 20 de octubre de 2012 .

${ }^{62}$ Desde estas premisas se propone la siguiente redacción del artículo I de la LIONDAU: «2. A los efectos de esta ley son personas con discapacidad aquellas que presenten deficiencias físicas, mentales, intelectuales o sensoriales que, al interactuar con diversas barreras, puedan impedir su participación plena y efectiva en la sociedad, en igualdad de condiciones con los demás. Únicamente podrá exigirse el reconocimiento de un grado de discapacidad del $33 \%$ para acceder a algunas prestaciones o medidas de acción positiva. A estos efectos, se considerarán que presentan una discapacidad en grado igual o superior al 33 por ciento los pensionistas de la Seguridad Social que tengan reconocida una pensión de incapacidad permanente en el grado de total, absoluta o gran invalidez, y a los pensionistas de clases pasivas que tengan reconocida una pensión de jubilación o de retiro por incapacidad permanente para el servicio o inutilidad. La acreditación del grado de discapacidad se realizará en los términos establecidos reglamentariamente $y$ tendrá validez en todo el territorio nacional».

${ }^{6}$ BOE núm. 299 de 15 de diciembre de 2006.

${ }^{64}$ Vid. PALACIOS, A., «La ley 39/2006 a la luz del modelo social y de la convención internacional» en BARRANCO AVILÉS, M.C., (coord.), Situaciones de dependencia, discapacidad $y$ derechos, Madrid, Dykinson, 2OII. 
medios de apoyo a la comunicación oral de las personas sordas, con discapacidad auditiva y sordociegas $^{65}$.

\section{IV.2. Cambios en el régimen general de capacidad jurídica}

En este ámbito se propone, en primer lugar, como cuestión previa la reforma de la actual regulación de la interrupción voluntaria del embarazo, para eliminar los supuestos que se consideran discriminatorios (no exactamente de la persona, pero sí del bien jurídico protegido) por motivos de discapacidad ${ }^{66}$. De esta forma deben derogarse los incisos que permiten ampliar el plazo para proceder a la interrupción del embarazo en los supuestos de «riesgo de graves anomalías en el feto» o cuando «se detecte en el feto una enfermedad extremadamente grave e incurable en el momento del diagnóstico $y$ así lo confirme un comité clínico». Conviene en cualquier caso aclarar que la CDPD no exige el cambio general de la ley de plazos, sino simplemente la eliminación de la posibilidad de ampliar estos plazos por razón de discapacidad.

Además, se considera conveniente optar por la derogación total de la institución de la incapacitación (artículos I99 y 200 del Código civil), y, consecuentemente, se propone la reforma del art. 322 del Código civil que establece quiénes están en plenitud de ejercicio en los derechos civiles y del art. I263 que se refiere a quiénes no pueden prestar su consentimiento para realizar actos civiles, ambos excluyentes para las personas «incapaces». Estas reformas adquieren una importancia central en tanto se proyectan en el resto de los ámbitos que serán analizados posteriormente.

La nueva regulación de la capacidad jurídica debe partir no del establecimiento de las causas que permiten la restricción de la capacidad, sino de un reconocimiento general de la igual capacidad jurídica (que englobaría la capacidad jurídica y la capacidad de obrar) de todas las personas mayores de edad, incluidas las personas con discapacidad, y de la exigencia de cumplir las obligaciones de accesibilidad y de realización de ajustes razonables en todos los ámbitos en los que deba ejercerse la capacidad jurídica (obligación que, con carácter específico, debe tenerse en cuenta en las propuestas de reforma de diferentes ámbitos ${ }^{67}$. Igualmente, debe establecerse de manera expresa que la necesidad de contar con medidas de apoyo no supone una limitación de la capacidad jurídica.

El reconocimiento de la igualdad en el ámbito de la capacidad jurídica debe complementarse con la articulación de un sistema de apoyo en la toma de decisiones que reemplace al actual sistema de sustitución. La regulación de este modelo de apoyos debería hacerse en un nuevo Título del Código civil denominado, «De las medidas de apoyo al ejercicio de la capacidad jurídica».

A mi modo de ver, el sistema de apoyo podría articularse en el caso español a través del reconocimiento de un derecho general a los apoyos que implicaría que todas las personas, y no sólo las personas con discapacidad, que se encuentren en una situación que les dificulte la toma de sus propias decisiones y el ejercicio de la capacidad jurídica I) tienen

${ }^{65}$ BOE núm. 255 de 24 de octubre de 2007 . Sobre la adaptación general de esta ley a la Convención Vid. CUENCA GÓMEZ, P. (ed), Los derechos de las personas sordas, Madrid, Dykinson, $20 \mathrm{o} 2$.

${ }^{66}$ Vid. sobre el carácter discriminatorio de estos supuestos, PALACIOS, A., El modelo social, cit., págs. I26 y RAMIRO AVILÉS, M.A., «Discapacidad, salud, sanidad e investigación» en CUENCA GÓMEZ, P. (ed.), Estudios sobre el impacto de la Convención Internacional sobre los Derechos de las Personas con Discapacidad en el Ordenamiento jurídico español, Madrid, Dykinson, 2010, págs. I03-I53.

${ }^{67}$ En este sentido se propone la siguiente redacción del artículo I99 del Código civil: «1.Todas las personas podrán ejercer su capacidad jurídica en igualdad de condiciones con las demás, incluidas las personas con discapacidades físicas, intelectuales $y$ sensoriales. 2. Los poderes públicos garantizarán la accesibilidad universal en todos los ámbitos en los que las personas deban ejercer su capacidad jurídica y realizarán los ajustes razonables que sean necesarios» 
derecho al uso y al reconocimiento de los apoyos informales con los que cuenten y a la prestación de los apoyos necesarios por parte de diferentes autoridades y operadores y 2 ) tienen el derecho a solicitar la formalización de estos apoyos a través del establecimiento en sede judicial de un plan personalizado de medidas de apoyo. Esta posibilidad podría convertirse en una obligación, que recae sobre determinadas sujetos cercanos a la persona beneficiaria del plan y sobre determinadas autoridades, cuando la inexistencia de dicho plan pueda impedir el ejercicio de la capacidad $u$ ocasionar un perjuicio grave a las personas que lo precisen $^{68}$.

Las figuras de de apoyo reemplazan, en relación con las personas mayores de edad, a las tradicionales instituciones de protección y representación vinculadas a la incapacitación, el tutor y el curador. Por tanto en la regulación de estas dos figuras, que deben quedar reservadas a los menores ${ }^{69}$, hay que eliminar cualquier referencia al «incapaz».

La función de apoyo -ya sea formal o informal- debe consistir en asistir a la persona en la toma de sus propias decisiones en diferentes modos y maneras respetando siempre su voluntad y sus preferencias. Las funciones de apoyo podrían ser desempeñadas tanto por personas físicas que tengan una relación de confianza con la persona apoyada como por instituciones públicas o privadas creadas para este fin y pueden ser desarrolladas por una o por varias personas o instituciones atendiendo a la voluntad y preferencias, situación y necesidades de la persona a la que se refieren. Para el nombramiento de las personas o instituciones de apoyo se deberían tener siempre en cuenta la opinión de la persona afectada.

En circunstancias excepcionales, cuando las personas por cualquier motivo (y no sólo por motivo de discapacidad) se encuentren en una situación que les impide conformar o expresar por cualquier medio su voluntad, se propone la articulación de apoyos obligatorios que pueden dar entrada a acciones puntuales de sustitución para evitar daños irreparables a las personas. En cualquier caso estas acciones de sustitución deben realizarse desde el modelo de apoyo respetando, por tanto, la identidad de la persona y decidiendo, en consecuencia, teniendo siempre en cuenta su historia de vida y sus circunstancias personales y sociales. Por ello en este caso, si la persona no puede designar a quién debe desempeñar la función de apoyo y no existe un régimen de autoprotección que se pronuncie sobre esta cuestión, se debe escoger a quienes tengan una relación de confianza

${ }^{68}$ Así, se propone la inclusión en el nuevo Título antes mencionado de los siguientes preceptos, entre otros:

Art. 200. 1. «Toda persona que así lo requiera contará con las medidas de apoyo necesarias para el pleno ejercicio de su capacidad jurídica. Estas medidas podrán establecerse a través de la creación de un plan personalizado de medidas de apoyo establecido por la autoridad judicial, que deberá estar sujeto a controles periódicos. 2. Las medidas de apoyo serán individualizadas, adecuadas y efectivas, en su establecimiento y funcionamiento se respetarán siempre los derechos, la voluntad y las preferencias de las personas $y$ se velará por evitar los posibles abusos, la influencia indebida y los conflictos de intereses»

Art. 201. «1.Toda persona que tenga dificultades en el ejercicio de su capacidad jurídica podrá solicitar el establecimiento de un plan personalizado de medidas de apoyo para el ejercicio de su capacidad jurídica, a través del procedimiento judicial establecido en los arts. $X Y$ ss. de la Ley de Enjuiciamiento Civil. También están legitimadas para iniciar este procedimiento las personas $y$ entidades señaladas en el art. $X$ de la Ley de Enjuiciamiento civil. 2. En todo caso, están obligados a promover el establecimiento judicial de un plan personalizado de medidas de apoyo cuando su inexistencia pueda impedir el ejercicio de la capacidad jurídica de la persona o causarle un perjuicio grave los parientes en línea recta o colaterales hasta el cuarto grado, el cónyuge o persona con análoga relación de afectividad de acuerdo con la ley, y la persona, física o jurídica, que desempeñe su atención inmediata. Podrán también promoverla las personas jurídicas legalmente habilitadas para la defensa de los derechos e intereses de las personas con discapacidad. 3. Con independencia del establecimiento de este plan, toda persona que tenga dificultades para el ejercicio de su capacidad jurídica tendrá derecho a que se le presten las medidas de apoyo necesarias en las actuaciones que realice ante las Administraciones y funcionarios públicos y al uso y reconocimiento de los apoyos que requiera para la adopción de sus decisiones».

${ }^{69}$ Aunque no puedo detenerme en el análisis de esta cuestión, conviene señalar que posiblemente también la regulación de la capacidad jurídica de los menores deba ser revisada, y que quizá el sistema de apoyo en la toma de decisiones pueda ser útil en este contexto. 
con la persona que les permita atribuirle voluntad y preferencias. Para el buen funcionamiento del sistema de apoyos se considera necesario establecer algunas incompatibilidades, regular las causas de extinción de la función de apoyo, y articular ciertas garantías (como suministrar información acerca del estado de los bienes patrimoniales e intereses personales, prestación de fianzas cuando se considere necesario, etc.).

Las salvaguardas en el buen funcionamiento de las medidas de apoyo, y en especial, la función de garantes que deben desempeñar la autoridad judicial y el Ministerio Fiscal, que se plasma también en diferentes ámbitos normativos concretos, deben ser en estas situaciones especialmente intensas. En todo caso, la obligación general de salvaguardar el buen funcionamiento del sistema de apoyos -la inexistencia de abusos, y de influencia indebida, el respeto a la voluntad y preferencias de la persona apoyada- no sólo recae en los jueces y en el Ministerio Fiscal, sino también en diferentes autoridades, funcionarios u operadores -Notarios, Registradores, facultativos, representantes sindicales, etc.- en función del tipo de acto de que se trate.

Como ya se advirtió, estas previsiones irradian en el ejercicio de diferentes derechos y en la realización de actos con trascendencia jurídica en diferentes ámbitos y en el ejercicio de diferentes derechos. Así, es necesario eliminar las limitaciones en el ejercicio de la capacidad y reconocer el derecho general a los apoyos por ejemplo, para contratar y prestar el consentimiento en general (art. I263 Código civil), para administrar bienes en general (art. 223 Código civil), para realizar un contrato de trabajo (art. 7 Estatuto de los Trabajadores), para ser parte en un proceso judicial (art. 6 LEC), para comparecer (art. 7 LEC), para ser testigo (art. 36I LEC), ser jurado (art. 8 Ley 5/I995 del Tribunal del Jurado), para otorgar escrituras (art. I56 RD 45/2007 del Notariado), hacer testamento (art. 665 Código civil. art. 607 Código civil), establecer un régimen de autoprotección (art. 223 Código civil), establecer un documento de instrucciones previas (art. II Ley 4I/2002 de autonomía del paciente) ${ }^{70}$, ejercer el derecho al sufragio (art. 3 Ley Orgánica 5/1985 del Régimen Electoral General ${ }^{\mathrm{I}}$ ), el derecho a la libertad sindical (art. I Ley Orgánica II/I985 de Libertad sindical ${ }^{72}$ ), el derecho de asociación (art. 3,a Ley Orgánica I/2002 reguladora del derecho de asociación $n^{73}$ ); la opción a la nacionalidad (art. 20 Código civil), el derecho al matrimonio (art. 56 Código civil); el derecho a la filiación no matrimonial (art. I24 Código civil), el derecho a la adopción (art. I76 Código civil), el derecho a capitulaciones matrimoniales, régimen económico del matrimonio (art. I330 Código civil), los derechos de posesión (art. 443 Código civil), para constituir el patrimonio protegido y al administrarlo (art. 3 Ley 4I/2003 de I8 de noviembre, de protección patrimonial de las personas con discapacidad y de modificación del Código Civil, de la Ley de Enjuiciamiento Civil y de la Normativa Tributaria con esta finalidad ${ }^{74}$ ), consentir el trasplante de órganos (art. 6 Ley 30/1979 de 27 de octubre, sobre extracción y trasplante de órganos ${ }^{75}$ ), para la donación de órganos (art. 9 Real Decreto 2070/1999 que Regula las Actividades de Obtención y Utilización Clínica de Órganos Humanos y la Coordinación Territorial en Materia de Donación y Trasplante de Órganos y Tejidos ${ }^{76}$ ), de gametos y preembriones (art. 5 Ley I4/2006 de técnicas de reproducción asistida ${ }^{77}$ ); para las técnicas de reproducción asistida (art. 3 Ley I4/2006); la interrupción voluntaria del embarazo (art. I3 Ley Orgánica 2/2010 de 3 de marzo, de salud sexual y reproductiva y de la interrupción voluntaria del

\footnotetext{
$7^{\circ 0}$ BOE núm. 274 de 15 de noviembre de 2002.

${ }^{71}$ BOE núm. I47 de 20 de junio de 1985.

${ }^{72}$ BOE núm. I89 de 8 de agosto de I985.

${ }^{73}$ BOE núm. 73 de 26 de marzo de 2002.

${ }^{74}$ BOE núm. 277 de I9 de noviembre de 2003.

75 BOE núm. 266 de 6 de noviembre de I979.

${ }^{76}$ BOE núm. 3 de 4 de enero de 2000.

77 BOE núm. I26 de 27 de mayo de 2006.
} 
embarazo $^{78}$ ), al consentir intromisiones en el honor, intimidad e imagen (art. 3 Ley Orgánica I/I982 de 5 de mayo, de Protección Civil del Derecho al Honor, a la Intimidad Personal y Familiar y a la Propia Imagen ${ }^{79}$ ), en los ingresos no voluntarios (art. 763 LEC), o al ejercer los derechos reconocidos a las personas en situación de dependencia (art. 3 de la Ley 39/2006), al elegir entre lengua de signos o medios de apoyo a la comunicación oral (art. I6 Ley 27/20007). Además, se debe prever expresamente en los diferentes ámbitos la validez de todas las actuaciones realizadas de conformidad con el plan personalizado de apoyo.

Obviamente, también el procedimiento de incapacitación debe ser reemplazado por su procedimiento orientado a determinar los apoyos necesarios para el ejercicio de la capacidad. Este procedimiento, de acuerdo con la propuesta anteriormente realizada, podría articularse como un proceso para el establecimiento de planes personalizados de medidas de apoyo para el ejercicio de la capacidad jurídica.

A mi modo de ver, al menos en una primera fase, este proceso debería tener carácter judicial y sustanciarse ante juzgados especializados con formación específica en esta materia. Podría iniciarse a instancia de la persona afectada, de los parientes más próximos o personas de su entorno más cercano, o de las entidades sin ánimo de lucro que representan a las personas con discapacidad que serán siempre parte cuando la persona beneficiaria sea una persona con discapacidad; de un juez de lo penal por la comisión de un delito; de un juez en general o del Ministerio Fiscal. El establecimiento de los planes personalizados de medidas de apoyo, salvo cuando exista oposición por parte de la persona beneficiaria o por cualquiera otra entre las legitimadas para instar la instauración de medidas de apoyo, podría sustanciarse de acuerdo con el procedimiento de jurisdicción voluntaria. La persona beneficiaria del plan debe ser la protagonista en el proceso respetándose siempre su voluntad y preferencias y en la evaluación de la necesidad de asistencia y de la adecuación de las medidas de apoyo se deberán tener en cuenta las circunstancias no sólo individuales, sino también sociales ${ }^{80}$.

Los planes personalizados de medidas de apoyo deben detallar de manera pormenorizada y ajustada a la situación y necesidades de la persona las áreas en las que se precisa asistencia y la figura o figuras de apoyo. Cuando se trate de una persona que no puede conformar o expresar por ningún medio su voluntad el plan podrá contemplar apoyos obligatorios que sustituyan a la persona en la toma de determinadas decisiones establecidas individualizadamente en la resolución y que deberán limitarse a aquellas cuya no adopción suponga un daño irreparable para la persona. Como se señaló, las acciones sustitutivas deberán respetar siempre la identidad de la persona en el sentido antes indicado.

En la resolución por la que se establezca un plan personalizado de medidas de apoyo deben establecerse controles específicos para garantizar su buen funcionamiento, evitar los abusos y la influencia indebida y deben articularse mecanismos de revisión periódica. En todo caso, esta revisión siempre deberá realizarse con la participación de la persona beneficiaria. La existencia de un plan personalizado de medidas de apoyo deberá gozar de publicidad registral para ser oponible a los terceros de buena fe y las autoridades y

\footnotetext{
${ }^{8}$ BOE núm. 55 de 4 de marzo de 20 o.

79 BOE núm. II5 de I4 de mayo de I982.

${ }^{80}$ En este sentido se considera necesaria la introducción de un artículo que señale lo siguiente «El tribunal acordará los dictámenes periciales que estime necesarios para obtener un conocimiento global de la situación de la persona. En todo caso, se acordará un dictamen pericial médico que deberá pronunciarse específicamente sobre las habilidades concretas de la persona en sus diferentes esferas de actuación $y$ un dictamen psico-social que deberá referirse a las actividades más frecuentes de la persona, su relación con su entorno familiar y afectivo, posible existencia de redes de apoyo etc. ».
} 
funcionarios públicos que intervengan en actos en los que participen personas que cuentan con estos planes deben comprobar su adecuado funcionamiento.

Para el adecuado funcionamiento del sistema de apoyo resultan esenciales instituciones como los poderes preventivos o instrucciones previas que permiten a las personas expresar anticipadamente su voluntad en previsión de tener dificultades o no poder expresarla en el futuro. Dada la importancia de este tipo de instrumentos, especialmente en relación con personas que pueden llegar a necesitar apoyos obligatorios, parece conveniente promover su establecimiento, regular nuevas figuras y mejorar la regulación de las existentes. En este punto, el término «autotutela» empleado por la legislación española, debe eliminarse y la regulación de esta materia efectuarse en el nuevo Título del Código civil relativo a las medidas de apoyo en el ejercicio de la capacidad jurídica. El derecho al establecimiento de un régimen de autoprotección, que pueda incluir medidas de apoyo para el ejercicio de la capacidad jurídica, con las previsiones y requisitos que se estimen adecuados a cada caso y circunstancia debe reconocerse a todas las personas que consideren que puede tener dificultades en el futuro en la toma de sus decisiones o que las que ya tienen pueden agravarse. Tanto en este ámbito, como en lo que se refiere en la expresión de instrucciones previas en materia sanitaria se propone eliminar la exigencia que las personas cuenten con plena capacidad de obrar. En la nueva regulación debería señalarse que las personas que lo precisen contarán con los apoyos necesarios para la expresión de su voluntad anticipada a través de estos instrumentos y que tal expresión deberá adecuarse, en su caso, al plan personalizado de medidas de apoyo.

IV.3. Cambios en las condiciones de ejercicio de los derechos y realización de actos jurídicos

Me referiré a continuación a algunos de los cambios más relevantes que se derivan de las propuestas de reforma de la normativa básica reguladora de los derechos de las personas con discapacidad y de la regulación civil de la incapacitación y que afectan a las condiciones básicas de ejercicio de diferentes derechos y realización de actos jurídicos.

\section{IV.3.I. Capacidad para realizar actos patrimoniales y personalísimos}

Por lo que respecta a la celebración de actos patrimoniales y en conexión con la reforma del art. I2 $_{3}$ del Código civil, relativo a la capacidad para prestar consentimiento ${ }^{8 \mathrm{r}}$, se considera que las personas que lo precisen deben contar con los apoyos necesarios para su realización y que la misma debe efectuarse, en su caso, de conformidad con el plan personalizado de medidas de apoyo. Los actos patrimoniales realizados con los apoyos precisos deberán considerarse plenamente válidos. En el plan personalizado de medidas de apoyo podrían establecerse especiales garantías, comunicación al Ministerio Fiscal o al propio juez, en relación con actos patrimoniales de especial trascendencia en función de la situación de la persona.

La capacidad natural exigida, como ya se dijo en nuestro sistema, para la realización de actos personalísimos debe desvincularse de referencias a la «competencia mental» y definirse en términos neutrales en relación con la discapacidad y las deficiencias.

\footnotetext{
${ }^{8 \mathrm{r}}$ Se propone la siguiente redacción alternativa del artículo 1263: «No pueden prestar consentimiento:1. Los menores no emancipados. 2. Las personas que se encuentran en una situación que les impide conformar o expresar su voluntad por cualquier medio. _Las personas que lo precisen tendrán derecho al uso, reconocimiento y prestación de las medidas de apoyo que resulten necesarias para expresar su consentimiento en todos los ámbitos. El consentimiento otorgado por una persona que cuenta con un plan personalizado de medidas de apoyo para el ejercicio de su capacidad jurídica de conformidad con las previsiones contenidas en dicho plan deberá considerarse plenamente válido. En todo caso, las autoridades o funcionarios públicos que puedan intervenir en los diferentes contratos deberán controlar el efectivo $y$ adecuado funcionamiento de las medidas de apoyo de acuerdo con lo señalado en los arts. xxx y ss. de este Código».
} 
La regulación de las condiciones para el ejercicio de estos actos debe centrarse en las «situaciones» y no en los «rasgos» de la persona. En este sentido, se propone establecer que no podrán realizar estos actos quienes se encuentren en una situación que les impida, por cualquier motivo, conformar o expresar su voluntad por cualquier medio.

En este ámbito (que afecta a actos tales como contraer matrimonio, otorgar testamento o reconocer la filiación) se proyecta también el derecho general a los apoyos y al establecimiento de un plan personalizado que tratan de facilitar la conformación, expresión y comunicación de esa voluntad. Los funcionarios y autoridades que intervengan en estos actos deben velar por el buen funcionamiento de las medidas y planes de apoyo ${ }^{82}$.

En la misma línea se propone la modificación del artículo 3 de la Ley del Régimen Electoral General que permite la restricción del derecho de sufragio de las personas internadas con autorización judicial y de las personas incapacitadas ${ }^{8}$.

\section{IV.3.2. Régimen de responsabilidad civil y penal}

Las personas con discapacidad o deficiencias deben considerarse responsables civiles en las mismas condiciones que los demás, esto es, cuando concurra culpa subjetiva, y, por tanto, siempre que se comprenda la ilicitud del acto. Por otro lado, la responsabilidad objetiva por actos de terceros debería limitarse a las personas que desempeñan apoyos obligatorios. Los contratos en los que intervienen personas con apoyos han de considerarse válidos si éstos han funcionado correctamente o se han realizado de conformidad con el plan personalizado y las personas que precisan apoyos deben considerarse responsables en este ámbito. En otro caso, estos contratos deben ser considerados anulables e incluso nulos.

\footnotetext{
${ }^{82}$ Así, por ejemplo, se aboga por dar el siguiente tenor a los artículos 662, 663 y 665 del Código civil, Art. 662. «Pueden testar todos aquellos a quienes la ley no lo prohíbe expresamente». Art. 663 «No podrán testar: 1. Los menores de catorce años de uno y otro sexo. 2. Las personas que se encuentran en una situación que les impide conformar o expresar su voluntad por cualquier medio». Art. 663 bis: "Cuando las personas cuenten con un plan personalizado de apoyo a la capacidad, el testamento se otorgará ante Notario, que velará porque las garantías previstas en el mencionado plan se cumplan. Art. $66_{5}$ «Las personas que lo precisen tendrán derecho al uso, reconocimiento $y$ prestación de las medidas de apoyo que resulten necesarias para otorgar testamento. El testamento otorgado por una persona que cuenta con un plan personalizado de medidas de apoyo para el ejercicio de su capacidad jurídica de conformidad con las previsiones contenidas en dicho plan deberá considerarse plenamente válido. En todo caso, el Notario deberá controlar el efectivo y adecuado funcionamiento de las medidas de apoyo de acuerdo con lo señalado en los arts. XXX Y ss. de este Código».
}

Y por reformar el artículo 56 en el siguiente sentido: «Quienes deseen contraer matrimonio acreditarán previamente, en expediente tramitado conforme a la legislación del Registro Civil, que reúnen los requisitos de idoneidad establecidos en este Código.

Si alguno de los contrayentes, por cualquier motivo, se encontrase en una situación que le impidiese conformar $y$ expresar su voluntad por cualquier medio, se exigirá dictamen pericial sobre su aptitud para prestar el consentimiento.

En todo caso, las personas que lo precisen tendrán derecho al uso, reconocimiento $y$ a la prestación de las medidas de apoyo que resulten necesarias para ejercer su derecho a contraer matrimonio. El consentimiento emitido conforme a un plan personalizado de apoyo al ejercicio de la capacidad debe considerarse plenamente válido. El encargado del Registro Civil controlará el efectivo y adecuado funcionamiento de las medidas de apoyo de acuerdo con lo establecido en este Código»..

${ }^{8}$ El precepto citado pasaría a establecer: «1. Carecen de derecho de sufragio: a. Los condenados por sentencia judicial firme a la pena principal o accesoria de privación del derecho de sufragio durante el tiempo de su cumplimiento. $b$. Los ingresados en un centro de salud mental con autorización judicial, durante el período que dure su internamiento siempre que en la autorización el juez declare expresamente la privación del ejercicio del derecho de sufragio. Solamente podrá declararse esta privación cuando la persona no pueda conformar o expresar por ningún medio su voluntad. Esta declaración deberá ser motivada atendiendo a la situación particular de la persona. c. Las personas que lo precisen tendrán derecho al uso, reconocimiento y prestación de los apoyos necesarios para el ejercicio del derecho de sufragio. El establecimiento de un plan personalizado de apoyos a través del procedimiento regulado en los arts. 757 y ss. de la Ley de Enjuiciamiento Civil no supondrá la privación del derecho de sufragio. d. Únicamente en aquellos casos en los que la persona se encuentre en una situación en la que no pueda conformar o expresar por ningún medio su voluntad $y$ preferencias el juez podrá privar a la persona del ejercicio de derecho de sufragio. En todo caso, tal privación deberá ser motivada atendiendo a la situación particular de la persona. En el supuesto de que esta sea apreciada, lo comunicarán al Registro Civil para que se proceda a la anotación correspondiente». 
Respecto de la responsabilidad penal, se propone que las eximentes y atenuantes no se basen directa o indirectamente en la discapacidad o las deficiencias y que se redefinan en términos neutrales relativos a las situaciones que impiden comprender la ilicitud de los $\operatorname{actos}^{84}$. Igualmente, se considera necesario eliminar la relación que se establece, en ocasiones de manera directa, entre la peligrosidad y el trastorno mental en la regulación de la imposición de medidas de seguridad. Únicamente cuando la persona se encuentre en una situación que le impida conocer el sentido de la pena y pueda deducirse un pronóstico de comportamiento futuro que revele la probabilidad de comisión de nuevos delitos se podrá decretar la imposición de una medida de seguridad privativa de libertad. Además, deben sustituirse términos peyorativos o estigmatizantes, como «enajenación», «minusválidos», o Centros o Unidades psiquiátricos por términos más neutros.

En relación con las personas internadas en Centros o Unidades de Salud mental se defiende el establecimiento de medidas encaminadas a favorecer el ejercicio de sus derechos, entre las que deben articularse medidas de apoyo. El consentimiento a tratamientos médicos deberá regirse, en todo caso, por la legislación sanitaria, que incluye en la propuesta aquí realizada el derecho a los apoyos, y por la regulación general del Reglamento Penitenciario que limita y establece garantías en relación con las situaciones en las que pueden imponerse tratamientos a las personas internadas en contra de su voluntad. En todo caso, la política de estos centros debe orientarse no sólo a la rehabilitación sino también a la inclusión social de las personas internadas.

En otro orden de cosas, se aboga por la incorporación de la discapacidad en la definición del delito de lesa humanidad regulado en el artículo 607 bis del Código Penal. Igualmente, se propone eliminar la referencia a la incapacidad de la víctima en la agravación de ciertos delitos y sustituir esta previsión por la necesidad de apoyos en la toma de decisiones de la víctima.

Finalmente, también en el ámbito penal se propone la derogación total del apartado del apartado 2 del artículo 156 en el que se despenaliza la esterilización forzosa en el caso de las personas con «grave deficiencia psíquica cuando aquella, haya sido autorizada por el juez, bien en el mismo procedimiento de incapacitación, bien en un expediente de jurisdicción voluntaria, tramitado con posterioridad al mismo, a petición del representante legal del incapaz, oído el dictamen de dos especialistas, el Ministerio Fiscal y previa exploración del incapaz».

\section{IV.3.3. Régimen de internamiento}

En este ámbito se aboga preferentemente por la derogación del artículo 763 de la LEC que permite el internamiento por razón de trastorno psíquico regulándose en la normativa pertinente al efecto las situaciones en las que cualquier persona, y no sólo las personas con discapacidad, puede ser ingresada sin su consentimiento.

En caso de que se opte por la reforma de este artículo se sugieren, entre otras modificaciones, sustituir el término internamiento que tiene una connotación sancionadora, por el término ingreso, eliminar la referencia al trastorno psíquico y definir en términos neutrales las circunstancias que permiten el ingreso involuntario, contemplar los apoyos, reducir los plazos para autorizar el ingreso en los casos de urgencia, aumentar

\footnotetext{
${ }^{84}$ Desde esta premisa se propone la siguiente redacción del artículo 20.I de la Ley Orgánica Io/ı995 de 23 de noviembre del Código Penal, BOE de núm. 28I de 24 de noviembre de I995: «Están exentos de responsabilidad criminal: 1. El que al tiempo de cometer la infracción penal se encuentre en una situación que le impida comprender la ilicitud del hecho o actuar conforme a esa comprensión. No se aplicará lo anterior cuando sea el propio sujeto quien provoque esta situación con el propósito de cometer el delito o hubiera previsto o debido prever su comisión». Y también la eliminación del inciso 3 que considera que está exento de responsabilidad criminal «El que, por sufrir alteraciones en la percepción desde el nacimiento o desde la infancia, tenga alterada gravemente la conciencia de la realidad».
} 
los controles, exigir informes de facultativos independientes, reducir los plazos de revisión judicial, y establecer en la resolución de ingreso la medidas terapéuticas aplicables ${ }^{85}$.

También se considera necesario introducir importantes mejoras en las leyes sanitarias que permiten tratamientos sin contar con el consentimiento del paciente.

\section{IV.3.4. Derechos del paciente}

El cambio principal que se plantea en esta materia consiste en exigir la accesibilidad de la información clínica y de la prestación del consentimiento que podrá otorgarse en los diferentes campos (tratamientos médicos, transplantes y donaciones de órganos, investigaciones, técnicas de reproducción asistida etc.) por cualquier medio

${ }^{85}$ Desde este enfoque la redacción del artículo 763 quedaría de la siguiente forma: «Ingreso no voluntario 1. Sólo se podrá decretar el ingreso de una persona en una institución para cuidados o tratamiento médico o asistencial sin su consentimiento en las siguientes situaciones:

1) En situaciones de salud pública o emergencia sanitaria decretadas por el Poder Ejecutivo o autoridad competente;

2) En situaciones de grave e inminente riesgo de muerte o de lesión grave e irreparable para la integridad fisica o psíquica de la persona o riesgo grave e inminente para terceros cuando la persona no esté en condiciones de decidirlo por sí misma y siempre y cuando se demuestre que ninguna otra medida menos restrictiva es posible o efectiva. La existencia del riesgo grave o inminente deberá acreditarse de forma fehaciente. La existencia de una discapacidad o de necesidad de apoyo en el ejercicio de su capacidad jurídica nunca podrá ser prueba suficiente para acreditar la concurrencia del mencionado riesgo.

2. El ingreso de una persona sin su consentimiento requerirá autorización judicial, que será recabada del tribunal del lugar donde resida la persona afectada por el ingreso. La autorización será previa a dicho ingreso salvo que razones de urgencia hicieren necesaria la inmediata adopción de la medida. En este caso, el responsable del centro en que se hubiere producido el ingreso deberá dar cuenta de éste al tribunal competente lo antes posible $y$, en todo caso, dentro del plazo de doce horas, a los efectos de que se proceda a la preceptiva ratificación de dicha medida, que deberá efectuarse en el plazo máximo de veinticuatro horas desde que el ingreso llegue a conocimiento del tribunal.

En los casos de ingresos urgentes, la competencia para la ratificación de la medida corresponderá al tribunal del lugar en que radique el centro donde se haya producido el ingreso. Dicho tribunal deberá actuar, en su caso, conforme a lo dispuesto en el apartado 3 del art. 757 de la presente Ley.

2. El ingreso de menores se realizará siempre en un establecimiento adecuado a su edad, previo informe de los servicios de asistencia al menor.

3. Para conceder la autorización o ratificar el ingreso que ya se ha efectuado, el tribunal dará siempre audiencia a la persona afectada por la decisión, al Ministerio Fiscal y a cualquier otra persona cuya comparecencia estime conveniente o le sea solicitada por el afectado por la medida. Además, $y$ sin perjuicio de que pueda practicar cualquier otra prueba que estime relevante para el caso, el tribunal deberá examinar por sí mismo a la persona de cuyo ingreso se trate, contar con un dictamen médico de un facultativo por él designado distinto o independiente de aquél donde la persona se encuentra ingresada, con un dictamen psicológico $y$ con un dictamen de trabajador social que de forma unánime determinen la necesidad del ingreso.

En todas las actuaciones, la persona afectada por la medida podrá disponer de representación y defensa en los términos señalados en el art. 758 de la presente Ley.

En todo caso, la decisión que el tribunal adopte en relación con el ingreso será susceptible de recurso de apelación.

4. En la misma resolución que acuerde el ingreso se determinará de forma precisa y detallada el tratamiento médico o asistencial a llevarse a cabo, el profesional o equipo responsable, la modalidad, el tiempo necesario y el mecanismo control del mismo. Cualquier otra práctica o tratamiento no autorizado en la sentencia judicial que sea objeto la persona se considerará falta grave del profesional o equipo responsable

En esta resolución se expresará la obligación de los facultativos que atiendan a la persona internada de informar periódicamente al tribunal sobre la necesidad de mantener la medida, sin perjuicio de los demás informes que el tribunal pueda requerir cuando lo crea pertinente.

Los informes periódicos serán emitidos al menos cada dos meses, a no ser que el tribunal, atendida la situación que motivó el internamiento, señale un plazo inferior.

Recibidos los referidos informes, el tribunal, previa la práctica, en su caso, de las actuaciones que estime imprescindibles, acordará lo procedente sobre la continuación o no del ingreso.

Sin perjuicio de lo dispuesto en los párrafos anteriores, cuando los facultativos que atiendan a la persona internada consideren que no es necesario mantener el ingreso darán el alta a la persona y lo comunicarán inmediatamente al tribunal competente» 
admitido comprensible, archivable y documentable que permita conocer la voluntad inequívoca de la persona. Estas exigencias no deben proyectarse únicamente sobre las personas con discapacidad, ni sobre todos los pacientes que lo precisen.

Se propone, además, la eliminación de las referencias al consentimiento por representación en relación con las personas «incapaces» y su sustitución por el consentimiento con apoyos (que supone el derecho general al uso, reconocimiento y prestación de apoyos y la exigencia de que el consentimiento se preste de conformidad, en su caso, con el plan personalizado establecido en sede judicial) ${ }^{86}$. Los facultativos que intervienen en las diferentes situaciones deben considerarse responsables del buen funcionamiento de las medidas y planes de apoyo, y, en ocasiones -cuando se trata de intervenciones especialmente importantes- se ha de establecerse la necesidad de comunicación o de autorización del Ministerio Fiscal.

Cuando concurren ciertas circunstancias y con especiales garantías, que tienen que implicar un mayor protagonismo al Ministerio Fiscal, se propone que las personas que desempeñan apoyos obligatorios pueden prestar su consentimiento en relación con tratamientos e intervenciones que afectan a las personas que no pueden conformar o expresar su voluntad por ningún medio, respetando siempre su identidad, y, por tanto, su historia de vida y sus circunstancias personales y sociales.

Por lo que respecta a los experimentos médicos, se propone también, la modificación, entre otros preceptos, del artículo 20 de la Ley I4/2007, de 3 de julio, de investigación biomédica ${ }^{87}$ para establecer el derecho a los apoyos y aumentar las garantías en la participación de las personas que no pueden expresar su voluntad por ningún medio

${ }^{86}$ En este sentido, se propone la siguiente redacción del artículo 9 de la Ley 4I/2002 de I4 de noviembre, básica reguladora de la autonomía del paciente y de derechos y obligaciones en materia de información y documentación clínica, «Limites del consentimiento informado y consentimiento por representación

1. La renuncia del paciente a recibir información está limitada por el interés de la salud del propio paciente, de terceros, de la colectividad y por las exigencias terapéuticas del caso. Cuando el paciente, una vez que haya contado con los apoyos necesarios, manifieste expresamente su deseo de no ser informado, se respetará su voluntad haciendo constar su renuncia documentalmente, sin perjuicio de la obtención de su consentimiento previo para la intervención.

2. Los facultativos podrán llevar a cabo las intervenciones clínicas indispensables en favor de la salud del paciente, sin necesidad de contar con su consentimiento, en los siguientes casos: a) Cuando existe riesgo para la salud pública a causa de razones sanitarias establecidas por la Ley. En todo caso, una vez adoptadas las medidas pertinentes, de conformidad con lo establecido en la Ley Orgánica 3/1986, se comunicarán a la autoridad judicial en el plazo máxime 24 horas siempre que dispongan el internamiento obligatorio de personas. b) Cuando existe riesgo inmediato grave para la integridad física o psíquica del enfermo y no es posible conseguir su autorización, consultando, cuando las circunstancias lo permitan, a sus familiares, a las personas de apoyo y a las personas vinculadas de hecho a él. La decisión deberá respetar la identidad de la persona $y$ tener en cuenta su historia de vida y sus circunstancias personales $y$ sociales.

3. Se otorgará el consentimiento por representación cuando, siendo el paciente menor de edad, no haya sido posible trasladar a éste información suficiente sobre el alcance de la intervención, después de utilizados los medios de comunicación adecuados a sus necesidades. En este caso, el consentimiento lo dará el representante legal del menor después de haber escuchado su opinión si tiene doce años cumplidos.

Cuando se trate de menores emancipados o con dieciséis años cumplidos, no cabe prestar el consentimiento por representación. Sin embargo, en caso de actuación de grave riesgo o cuando el menor precise de apoyos intensos, según el criterio del facultativo, los padres serán informados y su opinión será tenida en cuenta para la toma de la decisión correspondiente.

4. La interrupción voluntaria del embarazo, la práctica de ensayos clínicos y la práctica de técnicas de reproducción humana asistida se rigen por lo establecido con carácter general sobre la mayoría de edad y por las disposiciones especiales de aplicación.

5. La prestación del consentimiento por representación será adecuada a las circunstancias y proporcionada a las necesidades que haya que atender, siempre en favor del paciente $y$ con respeto a su dignidad personal. El paciente participará en la medida de lo posible en la toma de decisiones a lo largo del proceso sanitario».

${ }^{87}$ BOE I59 4 de julio de 2007. 
en investigaciones médicas estableciéndose el deber de respetar siempre su identidad en el sentido antes apuntado ${ }^{88}$.

\section{IV.3.5. Capacidad ante operadores jurídicos clave y en el ámbito laboral}

En este ámbito se incluye, en primer lugar, la propuesta de reforma de la regulación de la capacidad procesal en el orden civil, administrativo, laboral etc. que en el sistema vigente resulta excluyente para las personas con discapacidad y les restringe el derecho de acceso a la justicia. Así, la legislación procesal debe incorporar la referencia expresa al cumplimiento de las exigencias de accesibilidad y de realización de ajustes razonables y, de nuevo, deben proyectarse en este ámbito el derecho general a los apoyos y los planes personalizados para permitir a las personas que tienen dificultades en la toma de sus decisiones actuar por sí mismas ante los tribunales. En este punto los jueces deben garantizar la prestación del apoyo, en su caso, y el buen funcionamiento de las medidas ${ }^{89}$. También la regulación de la capacidad general de actuar ante las Administraciones públicas debe modificarse en idéntico sentido.

En esta materia adquieren también relevancia las actuaciones ante otras autoridades públicas, Notarios, Registradores, y funcionarios en general -para realizar actos patrimoniales, personalísimos o ejercer derechos como otorgar capitulaciones, participar como testigos en escritura, optar por la nacionalidad, otorgar testamento o contraer matrimonio etc.- sobre las que, al igual que sucede con los jueces, recae la obligación de reconocer y garantizar la prestación de los apoyos y de vigilar la actuación conforme con el

${ }^{88}$ Este precepto podría quedar redactado en los siguientes términos: «1. La investigación sobre una persona menor o sobre una persona mayor de edad que no pueda conformar o expresar por ningún medio su voluntad $y$ sus preferencias únicamente podrá ser realizada si concurren las siguientes condiciones:

a) Que los resultados de la investigación puedan producir beneficios reales o directos para su salud.

b) Que no se pueda realizar una investigación de eficacia comparable en individuos capaces de otorgar su consentimiento.

c) Que la persona que vaya a participar en la investigación haya sido informada por cualquier medio que le resulte comprensible de sus derechos $y$ de los límites prescritos en esta Ley y la normativa que la desarrolle para su protección.

d) Que los representantes legales de la persona que vaya a participar en la investigación o las personas que desempeñen apoyos obligatorios hayan prestado su consentimiento por escrito o por cualquier medio comprensible, archivable $y$ documentable, después de haber recibido la información establecida en el artículo 15. Los representantes legales $y$ las personas de apoyo tendrán en cuenta los deseos u objeciones previamente expresados por la persona afectada, su identidad, su historia de vida y sus circunstancias personales y sociales. En estos casos se actuará, además, conforme a lo previsto en el apartado 1 del artículo 4 de esta Ley.

2. Cuando sea previsible que la investigación no vaya a producir resultados en beneficio directo para la salud de los sujetos referidos en el apartado 1 de este artículo, la investigación podrá ser autorizada de forma excepcional si concurren, además de los requisitos contenidos en los párrafos b), c) y d) del apartado anterior, las siguientes condiciones:

a) Que la investigación tenga el objeto de contribuir, a través de mejoras significativas en la comprensión de la enfermedad o condición del individuo, a un resultado beneficioso para otras personas de la misma edad o con la misma enfermedad o condición, en un plazo razonable.

b) Que la investigación entrañe un riesgo y una carga mínimos para el individuo participante.

c) Que la autorización de la investigación se ponga en conocimiento del Ministerio Fiscal»

${ }^{89}$ De este modo se propone, por ejemplo, la siguiente redacción del artículo 6 de la LEC: «Las personas con discapacidad tendrán derecho al cumplimiento de las exigencias de accesibilidad y a la realización de los ajustes razonables que resulten necesarios para garantizar su capacidad para ser parte en los procesos ante los tribunales civiles. Las personas que lo precisen tendrán derecho al reconocimiento y a la prestación de las medidas de apoyo que se consideren necesarias para poder ser parte. Las personas que cuentan con un plan personalizado de medidas de apoyo para el ejercicio de su capacidad jurídica tienen plena capacidad para ser parte. En todo caso, el juez interviniente en el proceso y el Ministerio Fiscal deben comprobar el efectivo y adecuado funcionamiento de las medidas de apoyo de acuerdo con lo previsto en el art. 215 del Código civil». En el mismo sentido debe modificarse la Ley del Procedimiento Laboral, la Ley de la Jurisdicción contencioso-administrativa. 
plan personalizado establecido en sede judicial y el buen funcionamiento general de estas medidas.

Se propone también la modificación de la actual regulación de las condiciones exigidas para poder ser jurado o testigo que excluyen a las personas con deficiencias y la contemplación también en esta materia de medidas de apoyo.

En el ámbito laboral se aboga por el reconocimiento expreso de la prohibición de discriminación por motivo de discapacidad y por la mención explícita de la obligación de cumplir con las exigencias de accesibilidad y de realización de ajustes razonables. La regulación de la capacidad para celebrar contratos de trabajo ${ }^{90}$ y el ejercicio de la libertad sindical $^{9 \mathrm{I}}$, de nuevo, tiene que contemplar el derecho general a los apoyos y a los planes personalizados para cumplir con la exigencia de igualdad también en estos ámbitos.

\section{Venciendo resistencias y planteando cuestiones clave}

Como antes se señaló la anunciada instauración en la legislación española de un modelo de apoyo en la toma de decisiones que suplante al actual sistema de sustitución se ha venido retrasando. Posiblemente sean varias las razones que explican el escaso avance en este terreno.

En primer lugar, el cambio de modelo que propugna el artículo i2 afecta a la regulación de materias de gran tradición jurídica y ciertamente consolidadas en algunos sectores del Ordenamiento jurídico -como sucede paradigmáticamente con la cuestión de la incapacitación- que se muestran de por sí especialmente resistentes a los cambios. En segundo lugar, esta modificación se proyecta en normas que se presentan y contemplan como orientadas a la «protección» de las personas con discapacidad por lo que su reforma es vista con desconfianza desde algunos sectores del movimiento de personas con discapacidad y por algunos actores relevantes en el funcionamiento del actual sistema de incapacitación que, si bien se muestran críticos con el sistema actual -o al menos con algunos aspectos de su funcionamiento en la práctica- temen que un nuevo modelo que reemplace completamente al anterior pueda conllevar el desamparo y la desprotección de las personas con discapacidad. En tercer lugar, la puesta en marcha del nuevo sistema exige,

${ }^{90}$ En este punto se considera necesario modificar el artículo 7 del Real Decreto Legislativo I/I995, de 24 de marzo, por el que se aprueba el texto refundido de la Ley del Estatuto de los Trabajadores en los siguientes términos: «Capacidad para contratar. Podrán contratar la prestación de su trabajo:

a. Las personas mayores de dieciocho años.

b. Los menores de dieciocho y mayores de dieciséis años, que vivan de forma independiente, con consentimiento de sus padres o tutores, o con autorización de la persona o institución que les tenga a su cargo.

c. Las personas que lo precisen tendrán derecho al uso, reconocimiento y a la prestación de las medidas de apoyo que puedan necesitar para realizar un contrato de trabajo. Los contratos de trabajo realizados por una persona que cuenta con un plan personalizado de apoyo para el ejercicio de su capacidad jurídica de conformidad con las previsiones contenidas en dicho plan deben considerarse plenamente válidos La autoridad laboral $\gamma$, en su caso, los representantes sindicales, supervisarán los contratos suscritos por la personas que precisan de apoyos para la toma de decisiones para garantizar que éstos han sido efectivos.

d. Los extranjeros, de acuerdo con lo dispuesto en la legislación específica sobre la materia»

${ }^{9}$ Se propone así la modificación del artículo i numerales I y 2 de la Ley orgánica de libertad sindical II/I985: "Las personas con discapacidad tienen derecho a la libertad sindical en igualdad de condiciones. Para garantizar este derecho se cumplirán las exigencias de accesibilidad $y$ se establecerán los ajustes razonables que resulten necesarios. Las personas que lo precisen tendrán derecho al uso, reconocimiento y a la prestación de las medidas de apoyo que puedan necesitar para el ejercicio de este derecho». 
como se señaló, dotar de medios materiales y humanos lo que en el momento actual marcado por la crisis económica se antoja complicado.

A mi modo de ver, es importante vencer estas resistencias concienciando de la necesidad del cambio. En efecto, el sistema de incapacitación y la tutela surgieron hace mucho tiempo para cubrir situaciones que no son las que actualmente se plantean y se inspiraron en principios alejados del discurso de los derechos humanos. Empeñarse en el mantenimiento de esta regulación o en introducir simplemente retoques de detalle manteniendo incólume su estructura básica implica incumplir una obligación internacional. Dado el escaso éxito de las reformas emprendidas en los últimos años para introducir un sistema de graduación de la capacidad, parece conveniente apostar por una reforma más profunda que cambie el nombre, el contenido y el sentido de las medidas en materia de capacidad jurídica.

Asimismo resulta esencial plantear una reforma equilibrada que tenga como principio rector la promoción de la autonomía de las personas con discapacidad, pero sin olvidar el principio de protección, eso sí, teniendo presente que la protección debe ser la estrictamente necesaria, que ha de respetar el derecho de las personas con discapacidad de cometer sus propios errores como parte del crecimiento y del florecimiento humano y que tiene que entrar en juego en función de la concurrencia de determinadas situaciones, en las que se pueden encontrar todas las personas, y no por razón de discapacidad.

Igualmente, resulta crucial desmantelar los argumentos que apelan al coste económico de las reformas demostrando, de un lado, que no es tan alto especialmente si se reconvierten instituciones existentes y que en ocasiones es prácticamente inexistente y, de otro, subrayando que se trata de una cuestión de derechos humanos y de una obligación asumida en el plano internacional por el Estado español que no puede ser postergada.

En este sentido, la implantación del sistema de apoyo en la toma de decisiones requiere una reforma legal comprometida, profunda y valiente. Pero además el nuevo enfoque en el tratamiento de la capacidad jurídica puede y debe adelantarse en sede de aplicación judicial en cumplimiento de los arts. 96 y io.2 de la Constitución española. En efecto, la CDPD es, desde su publicación y entrada en vigor, en virtud de lo establecido en el art. $96 \mathrm{CE}$, parte del orden jurídico interno ${ }^{92}$ y sus disposiciones deben aplicarse con carácter preferente a las normas nacionales que se enfrenten con su contenido. Pero, además, según lo establecido en el art. I0.2 CE las normas constitucionales sobre derechos fundamentales y el conjunto del Ordenamiento jurídico español, deben ser interpretadas de conformidad con la CDPD ${ }^{93}$. Ello permite soluciones como recurrir a la curatela, interpretada según el modelo de apoyo, desterrando la tutela, hasta que se produzca la reforma legal o que el mismo juez establezca las medidas de apoyo en la sentencia.

Ahora bien, el cambio de paradigma desde el modelo de sustitución al modelo de apoyo depende no sólo de su implantación a través de una reforma legal, sino que también, y de modo posiblemente aún más relevante, de su proyección social. Por esta razón, es imprescindible la formación de los operadores jurídicos y de los profesionales de diferentes ámbitos y la educación de la sociedad en general en el modelo social y, por ende, en la contemplación de las personas con discapacidadcomo sujetos capaces, en determinadas situaciones con ciertas adaptaciónes (apoyos), de tomar sus propias decisiones y ejercer sus

\footnotetext{
$9^{2}$ «Los tratados internacionales válidamente celebrados, una vez publicados oficialmente en España, formarán parte del ordenamiento interno. Sus disposiciones sólo podrán ser derogadas, modificadas o suspendidas en la forma prevista en los propios tratados o de acuerdo con las normas generales del Derecho Internacional».

${ }^{93}$ Establece el art. I0.2 que «Las normas relativas a los derechos fundamentales y a las libertades que la Constitución reconoce, se interpretarán de conformidad con la Declaración Universal de Derechos Humanos y los tratados y acuerdos internacionales sobre las mismas materias ratificados por España».
} 
derechos en igualdad de condiciones con los demás. Igualmente es imprescindible la formación y la capacitación de las personas con discapacidad, que deben tener un papel central en el diseño e implementación del sistema, de sus familias y de las propias personas de apoyo ${ }^{94}$.

En cualquier caso, el éxito de la nueva visión de la capacidad jurídica contenida en el artículo i2 de la CDPD depende de un modo esencial del éxito general de este Tratado. En efecto, la igualdad en el ejercicio de la capacidad jurídica y el funcionamiento efectivo del sistema de apoyo parece una meta mucho más realizable en una sociedad en la que las personas con discapacidad tienen derecho a una eduación inclusiva, a la vida independiente y a ser incluidos en la comunidad, en la que se cumplen las exigencias de accesibilidad y ajustes razonables etc. Se trata, en todo caso, de una meta hacia la que debemos avanzar inexcusablemente. La historia de los derechos humanos puede ser contemplada como una historia de realización de utopías. También las personas con discapacidad deben formar parte de esta historia como protagonistas principales.

\section{Bibliografía:}

ASÍS ROIG, R. DE, «Sobre la capacidad» en BARIFFI, F. y PALACIOS, A., (coords.), Capacidad Jurídica, Discapacidad y Derechos Humanos: una revisión desde la Convención Internacional sobre los Derechos de las Personas con Discapacidad, Buenos Aires, Ediar, 2012, págs. 13-29.

ASÍS ROIG, R. DE, «La incursión de la discapacidad en la teoría de los derechos: posibilidad, elección, Derecho y Poder» en CAMPOY CERVERA, I., (ed.), Los derechos de las personas con discapacidad: perspectivas sociales, políticas, jurídicas y filosóficas, Madrid, Dykinson, 2004, págs. 59-73.

ASÍS ROIG, R. DE y otros, Sobre la accesibilidad universal en el Derecho, Cuadernos del Instituto de Derechos Humanos Bartolomé de las Casas, Madrid, Dykinson, 2007.

BARIFFI, F., «Capacidad jurídica y capacidad de obrar de las personas con discapacidad a la luz de la Convención de la ONU» en PÉREZ BUENO, L.C. (dir.) y SASTRE, A., (coord.), Hacia un Derecho de la Discapacidad, Estudios en Homenaje a Rafael de Lorenzo, Pamplona, Thomson Reuters Aranzadi, 2009, págs. 353-390.

BARTON, L., (comp.) Discapacidad $y$ sociedad, Madrid, Morata, I998.

BASTIDA FREIJEDO, F.J. y otros, Teoría General de los Derechos Fundamentales en la Constitución Española de 1978, Madrid, Tecnos, 2004.

CAMPO IZQUIERDO, A.L., «Comentarios a la Sentencia del Tribunal Supremo de 29/04/2009. Una comparativa en relación con la Sentencia del Tribunal. Supremo de 3I/I2/I99I», disponible en http://www.el-observatorio.org/wp-content/uploads/2009/05/comentario-comparativo-sentencia29deabrilde2009.pdf; fecha de consulta 20 de noviembre de $20 \mathrm{I} 2$.

CAMPOY CERVERA, I., «La discapacidad y su tratamiento conforme a la Constitución española de I978» en CAMPOY, I. Y PALACIOS, A. (eds.), Igualdad, No Discriminación y Discapacidad. Una visión integradora de las realidades española y argentina, Madrid, Dykinson, 2007, págs. I45-207.

COMES MUÑOZ, E. Y ESCALONILLA MORALES, B.M., «Discapacidad y procedimiento de incapacitación» en LAORDEN, J., (dir.), Los derechos de las personas con discapacidad, Vol. I, Aspectos jurídicos, Madrid, CGPJ, 2007 , págs. $169-226$.

CUENCA GÓMEZ, P., Los derechos de las personas con discapacidad, Madrid, Cuadernos de la Cátedra de Democracia y Derechos Humanos de la Universidad de Alcalá y el Defensor del Pueblo, 20ı2,

CUENCA GÓMEZ, P. (ed), Los derechos de las personas sordas, Madrid, Dykinson, $20 \mathrm{or}$.

CUENCA GÓMEZ, P., «La capacidad jurídica de las personas con discapacidad: el art.I2 de la Convención de la ONU y su impacto en el Ordenamiento jurídico español», Derechos y libertades, núm. 24, 20II, págs. 7496.

DE CASTRO, F., Derecho civil de España, T.II, Madrid, Civitas, I984.

DE LORENZO, R. DE Y CABRA, M.A., «Análisis de la nueva legislación sobre no discriminación, acción positiva y accesibilidad universal» en DE LORENZO GARCÍA, R. Y PÉREZ BUENO, L.C, Tratado sobre discapacidad, Pamplona, Thomson, Aranzadi, 2007, págs. 65I-697.

\footnotetext{
${ }^{94}$ Se trata de obligaciones que aparecen específicamente contempladas en diferentes preceptos de la CDPD.
} 
DÍEZ-PICAZO, L., Sistema de derecho civil. Volumen I, II ${ }^{\mathrm{a}}$ ed., Madrid, Tecnos, 2003.

GUILARTE MARTÍN-CALERO, C., La curatela en el nuevo sistema de capacidad graduable, Madrid, McGraw-Hill Interamericana de España, I997.

PALACIOS, A., «La ley 39/2006 a la luz del modelo social y de la convención internacional» en BARRANCO AVILÉS, M.C., (coord.), Situaciones de dependencia, discapacidad y derechos, Madrid, Dykinson, 201 I.

PALACIOS, A., El modelo social de la discapacidad. Orígenes, caracterización y plasmación en la Convención Internacional sobre los derechos de las personas con discapacidad, Colección CERMI, Madrid, CINCA, 2008.

PALACIOS, A., «Consultative meeting with stakeholders on legal measures key for the ratification and effective implementation of the CRPD » (ponencia presentada en el marco del Estudio del Alto Comisionado de las Naciones Unidas para los Derechos Humanos sobre medidas jurídicas esenciales para la ratificación y la aplicación efectiva de la Convención sobre los Derechos de las Personas con Discapacidad, Geneva, 24 October 2008).

PALACIOS, A., «¿ Modelo rehabilitador o modelo social?» en CAMPOY CERVERA, I. Y PALACIOS, A., (coords.), Igualdad No Discriminación y Discapacidad. Una visión integradora de las realidades española y argentina, Madrid, Dykinson, 2007, págs. 243-305.

PALACIOS, A. Y BARIFFI, F., La discapacidad como una cuestión de derechos humanos. Una aproximación a la Convención Internacional sobre los derechos de las personas con discapacidad, Madrid, Cinca, Colección Telefónica Accesible, 2007, págs. 66 y ss.

PÉREZ DE ONTIVEROS BAQUERO, C., «Comentario a las sentencia de 29 de abril de 2009», Cuadernos Civitas de Jurisprudencia Civil, núm. 82, enero-abril 20 ıо.

PÉREZ DE ONTIVEROS, C., «La Capacidad Jurídica y la Capacidad de Obrar. El artículo i2 de la Convención y sus implicaciones en el derecho privado español», Derecho privado y Constitución, núm. 23, 2009.

PÉREZ DE ONTIVEROS, C., «La capacidad jurídica y la capacidad de obrar: el artículo i2 de la Convención y sus implicaciones en el Derecho Privado español»,, Capacidad Jurídica y Discapacidad. Un Estudio de Derecho Privado Comparado a la luz de la Convención Internacional sobre los Derechos de las Personas con Discapacidad, Cuaderno de trabajo núm. 7, España: Derecho Común, Congreso Permanente sobre Discapacidad y Derechos Humanos, Cáceres, Aprosuba, 2009, págs.3I-49, disponible en: http://www.convenciondiscapacidad.es/Capacidad.html; fecha de consulta I de noviembre de $20 \mathrm{o} 2$.

QUINN, G., «An ideas paper on Legal Capacity» Disability, European Foundation Center, Bruselas, 2009, disponible en www.efc.be/Networking/InterestGroupsAndFora/.../EFCGQfinal.doc; fecha de consulta IO de noviembre de 2012 .

RAMIRO AVILÉS, M.A., «Discapacidad, salud, sanidad e investigación» en CUENCA GÓMEZ, P. (ed.), Estudios sobre el impacto de la Convención Internacional sobre los Derechos de las Personas con Discapacidad en el Ordenamiento jurídico español, Madrid, Dykinson, 2010, págs. I03-153.

RAMOS CHAPARRO, E., Ciudadanía y Familia: Los Estados Civiles de la Persona, Barcelona, Ed. Cedes, I999.

ROVIRA SUEIRO, E., La relevancia de la voluntad de la persona para afrontar su propia discapacidad, Madrid, Ed. Ramón Areces, 2006

SANTOS MORON, M.J., Incapacitados y derechos de la personalidad: tratamientos médicos: honor, intimidad e imagen, Madrid, Escuela Libre, 2000.

SEOANE RODRÍGUEZ, J.A. y ÁLVAREZ LATA, N., «El proceso de toma de decisiones de la persona con discapacidad: una revisión de los modelos de representación y guarda a la luz de la Convención sobre los derecho de las personas con discapacidad», Derecho privado y Constitución, núm. 4, 20Io, págs. II-66.

SOTO RUIZ, J.J., «El estatus jurídico de las personas con discapacidad en las leyes de cabecera del ordenamiento jurídico privado» en DE LORENZO, R., Y PÉREZ BUENO, L.C., (dirs.), Tratado sobre Discapacidad, Pamplona, Thomson, Aranzadi, 2007, págs. 577-622.

\section{Documentos:}

Informe «Capacidad jurídica y discapacidad. Propuestas para la adaptación normativa del ordenamiento jurídico español al artículo I2 de la CDPD» puede encontrarse un desarrollo detallado de las propuestas de reforma a las que aludiré en este apartado. Este informe está disponible en http://www.uc3m.es/portal/page/portal/instituto_derechos_humanos/sala_prensa/comunicados_de_pre nsa/informe_23/informe_23.pdf; fecha de consulta I de octubre de 2012. 
Informe sobre las medidas necesarias para la adaptación de la Legislación a la Convención de la ONU sobre los Derechos de las Personas con Discapacidad» elaborado por una Comisión Interministerial y aprobado por el Consejo de Ministros el 30 de marzo de 2010

Informe Alternativo España 20I0 realizado por el CERMI disponible en http://www.cermi.es/esES/Novedades\%2oe\%2oinformaci\%C3\%B3n\%2ode\%2ointeres/Paginas/Inicio.aspx?TSMEIdPub=II97; fecha de consulta 20 de octubre de 2012 .

Informe sobre medidas adoptadas en cumplimiento de Convención Internacional sobre los Derechos de las Personas con Discapacidad presentado ante el Comité sobre los Derechos de las Personas con Discapacidad en cumplimiento de la obligación establecida en el art. 35 de la Convención el 5 de mayo de 2010.

Informe que el Alto Comisionado de Naciones Unidas para los Derechos Humanos presentó al Comité Especial en su Sexta Reunión denominado «Capacidad jurídica», «Informe presentado por el Alto Comisionado para los Derechos Humanos de Naciones Unidas sobre Capacidad Jurídica» para la Sexta reunión del Comité Especial de la Convención sobre discapacidad, http://www.un.org/esa/socdev/enable/rights/documents/ahcGohchrlegalcap.doc., fecha de consulta io de septiembre de 2011 .

International Disability Alliance, «Principios para la implementación del artículo I2 de la CDPD» disponible en http://www.internationaldisabilityalliance.org; fecha de consulta 25 de noviembre de 2012.

Observaciones pueden consultarse en la web del Comité: http://www.ohchr.org/EN/HRBodies/CRPD/Pages/Session6.aspx; fecha de consulta I5 de noviembre de 2012.

\section{Textos legales y jurisprudenciales:}

Constitución española de I978, BOE núm. 3II de 29 de diciembre de I978

Convención Internacional sobre los Derechos de las Personas con Discapacidad, BOE núm. 96 de 2I de abril de 2008.

Código civil, BOE núm. 206 de 25 de julio de 1889

Ley Orgánica 2/201o de 3 de marzo, de salud sexual y reproductiva y de la interrupción voluntaria del embarazo, BOE núm. 55 de 4 de marzo de 20 io.

Ley Orgánica I/2002 reguladora del derecho de asociación, BOE núm. 73 de 26 de marzo de 2002.

Ley Orgánica Io/I995 de 23 de noviembre del Código Penal, BOE de núm. 28I de 24 de noviembre de I995

Ley Orgánica II/I985 de Libertad sindical, BOE núm. I89 de 8 de agosto de I985.

Ley Orgánica 5/1985 del Régimen Electoral General, BOE núm. I47 de 20 de junio de 1985.

Ley Orgánica I/ı982 de 5 de mayo, de Protección Civil del Derecho al Honor, a la

Intimidad Personal y Familiar y a la Propia Imagen, BOE núm. II5 de I4 de mayo de I982.

Ley 26/20II, de I de agosto, de adaptación normativa a la Convención Internacional sobre los Derechos de las Personas con Discapacidad, BOE núm. I84 de 2 de agosto de 2011.

Ley I/2009, de 25 de marzo, de reforma de la Ley de 8 de junio de I957, sobre el Registro Civil, en materia de incapacitaciones, cargos tutelares y administradores de patrimonios protegidos, de la Ley 4I/2003, de I8 de noviembre, sobre protección patrimonial de las personas con discapacidad y de modificación del Código Civil y de la Ley de Enjuiciamiento Civil de la normativa tributaria con esta finalidad, BOE núm. 73 de 26 de marzo de 2009 .

Ley $27 / 2007$ de 23 de octubre por la que se reconocen las lenguas de signos españolas y se regulan los medios de apoyo a la comunicación oral de las personas sordas, con discapacidad auditiva y sordociegas, BOE núm. 255 de 24 de octubre de 2007.

Ley 39/2006 de I4 de diciembre, de Promoción de la Autonomía Personal y Atención a las Personas en Situación de Dependencia, BOE núm. 299 de 15 de diciembre de 2006.

Ley I4/2006 de técnicas de reproducción asistida, BOE núm. I26 de 27 de mayo de 2006

Ley 4I/2003 de I 8 de noviembre, de protección patrimonial de las personas con discapacidad y de modificación del Código Civil, de la Ley de Enjuiciamiento Civil y de la Normativa Tributaria con esta finalidad, BOE núm. 73 de 26 de marzo de 2002. 
Ley 5I/2003 de Igualdad de Oportunidades, No Discriminación y Accesibilidad Universal, BOE núm. 289 de 3 de abril de 2003 .

Ley 4I/2002 de autonomía del paciente, BOE núm. 274 de I5 de noviembre de 2002.

Ley I/2000 de 7 de enero Enjuiciamiento civil, BOE núm. 7 de 8 de enero de 2000.

Ley 5/I995, de 22 de mayo, del Tribunal del Jurado BOE núm. I22 de 23 de mayo de 1995

Ley I3/1983, de 24 de octubre, de reforma del Código Civil en materia de tutela, BOE núm. 256 de 26 de octubre.

Ley I3/82 de Integración Social de los Minusválidos, BOE núm. I03 de 30 de abril de I982.

Ley 30/1979 de 27 de octubre, sobre extracción y trasplante de órganos, BOE núm. 266 de 6 de noviembre de I979. Real Decreto 2070/I999 que Regula las Actividades de Obtención y Utilización Clínica de Órganos Humanos y la Coordinación Territorial en Materia de Donación y Trasplante de Órganos y Tejidos, BOE núm. 3 de 4 de enero de 2000.

Real Decreto Legislativo I/1995, de 24 de marzo, por el que se aprueba el texto refundido de la Ley del Estatuto de los Trabajadores, BOE núm. 75 de 29 de marzo de 1995 .

Reglamento Notarial de I944.

Sentencia del Tribunal Constitucional 3II/2000 de I8 de diciembre, RTC 2000/3I3.

Sentencia del Tribunal Constitucional 269/1994 de 3 de octubre RTC/1994/269.

Sentencia de la Audiencia Provincial de Navarra de I4 junio 2005, AC 2005/18I3.

Sentencia del Tribunal Constitucional I74/2002, de i9 de octubre.

Sentencia del Tribunal Supremo 282/2009, de 29 de abril de 2009, RJ 2009/290I. 